Ann. Génét. Sél. anim., I978, 10 (I), 99-124.

\title{
Revue bibliographique
}

\section{Variations génétiques de l'efficacité alimentaire chez le porc en croissance : interaction avec les conditions nutritionnelles (1)}

\author{
L. OLLIVIER et Y. HENRY
}

Station de Génétique quantitative et appliquée, Station de Recherches sur l'Élevage des Porcs, Centre national de Recherches zootechniques, I.N.R.A., $7835^{\circ}$ Jouy-en-Josas, France

\section{Résumé}

Cet article est une revue bibliographique sur les aspects génétiques de l'efficacité alimentaire. D'une manière générale, le type génétique a peu d'effet sur l'utilisation digestive des nutriments. Par contre, l'utilisation de l'énergie métabolisable, que ce soit pour l'entretien ou pour la croissance, est fortement dépendante du type génétique. Cette variabilité résulte principalement, pour le besoin énergétique d'entretien, de l'intensité du métabolisme de base et de l'activité physique des animaux, et, pour les besoins de croissance, de l'importance relative des dépôts de protéines et de lipides. Cette variabilité génétique se retrouve dans l'efficacité alimentaire globale. Intra-race, l'indice de consommation apparaît comme un caractère polygénique d'héritabilité moyenne ( $0, I_{4}$ à 0,56 dans les races européennes actuelles) et peu dépendant des gènes individuellement identifiables. Entre races, cette variabilité se traduit par une différence de 0,42 point entre les races européennes extrêmes et par un effet d'hétérosis du croisement simple de 3 p. roo en moyenne. Enfin, dans le temps, l'évolution génétique des races semble s'accélérer depuis une quinzaine d'années et les progrès observés sux dix ans peuvent égaler l'étendue de variation des races à un moment donné. La variabilité génétique se manifeste en outre dans la réponse du Porc à des apports nutritionnels variés. Les modifications de l'apport énergétique obtenues en alimentation ad libitum par des variations de concentration énergétique n'entraînent cependant pas de réponse différente selon la race en indice de consommation, le coût énergétique du gain n'étant pas affecté. Si l'apport énergétique est restreint par rationnement, l'amélioration de l'efficacité alimentaire est plus nette, mais une réponse inverse est obtenue dans certaines lignées. L'élévation du taux azoté en alimentation ad libitum a des effets uniformément favorables sur l'indice de consommation, sauf en fin d'engraissement où cet effet favorable se limite aux races à fort développement musculaire, exigeantes en protéines et lysine. En alimentation rationnée, seul le type maigre accroît ses dépôts de tissus maigres en réponse à un apport protéique accru, sans que l'indice de consommation s'en trouve nécessairement amélioré.

(r) Communication présentée à la $28^{\mathrm{e}}$ réunion annuelle de la Fédération européenne de Zootechnie, Bruxelles, 22-28 août 1977 . 


\section{Introduction}

L'efficacité alimentaire est généralement exprimée sous la forme du rapport de la consommation d'aliment (C) sur le gain de poids (G). C est le plus souvent exprimé en poids d'aliment, mais parfois en énergie (digestible, métabolisable ou nette). $\mathrm{G}$ est généralement exprimé en poids vif, éventuellement vide, mais parfois aussi en poids de carcasse ou de tissu maigre, celui-ci pouvant être mesuré directement par dissection ou estimé indirectement. De plus les deux variables C et $\mathrm{G}$ peuvent être combinées entre elles de diverses façons, soit sous forme d'un rapport, $\mathrm{C} / \mathrm{G}$ (indice de consommation) ou $\mathrm{G} / \mathrm{C}$ (efficacité alimentaire), soit sous forme d'une combinaison linéaire, $\mathrm{C}$ pouvant être corrigé par régression en fonction de $\mathrm{G}$ et parfois en plus en fonction du poids moyen, en vue d'éliminer autant que possible les variations dues à l'entretien. D'autre part, l'efficacité alimentaire peut être déterminée dans un intervalle de poids, un intervalle d'âge, ou plus rarement pour une quantité donnée d'aliment. Le problème du choix de la meilleure mesure de l'efficacité alimentaire a été discuté en particulier par SuTHERLAND (1965), d'un point de vue biométrique, et par RoBIson et BERRUECos (I973) dans le cas particulier du Porc. Ces auteurs s'accordent à reconnaître la validité du critère classiquement retenu $\mathrm{C} / \mathrm{G}$ (poids vif) pour les études génétiques, malgré son caractère très global.

Les recherches menées dans ce domaine par les nutritionistes et par les généticiens ont souvent fait ressortir l'incompréhension mutuelle, dont certains aspects ont été analysés récemment par FowLER et al. (I976), entre ceux qui cherchent à expliquer et ceux qui cherchent à améliorer (incompréhension dont on pourrait trouver des équivalents dans d'autres secteurs de la biologie). Pour ce qui est de l'efficacité alimentaire du Porc, les premiers s'intéressent notamment à ses composantes énergétiques sur le plan de l'utilisation digestive et métabolique, les seconds à l'efficacité alimentaire globale (ou zootechnique) et les deux se retrouvent sur le terrain des interactions génotype-nutrition. En traitant successivement ces trois aspects de la variabilité génétique de l'efficacité alimentaire, nous espérons montrer qu'ils sont interdépendants et ainsi favoriser peut-être un dialogue plus fructueux entre les diverses disciplines intéressées.

\section{I. - Variations génétiques des composantes énergétiques de l'efficacité alimentaire}

Les variations génétiques de l'utilisation de l'énergie chez le porc résident dans des différences d'utilisation digestive ou métabolique pour l'entretien et la croissance, suivant la nature et l'importance des dépôts (protéines, lipides). Au plan métabolique, les facteurs génétiques peuvent in fluer sur les processus de synthèse et de catabolisme tant des lipides que des protéines tissulaires.

\section{I. - Variations de la disponibilité en énergie métabolisable}

D'une façon générale, le type génétique ne semble pas affecter l'utilisation digestive des nutriments, énergétiques et azotés, de même que le pourcentage d'énergie métabolisable (EM) dans la ration. Cela ressort de la comparaison de 


\section{TABLEAU $\mathbf{I}$}

Variation de l'utilisation digestive de l'énergie en fonction du type génétique (')

(SHARMA et al., I97I)

Breed differences in apparent digestibility of energy (ADE)

\begin{tabular}{|c|c|c|c|}
\hline $\begin{array}{c}\text { Race } \\
\text { Breed }\end{array}$ & Yorkshire & Lacombe & \\
\hline $\begin{array}{l}\text { CUD E }(A D E)\left({ }^{2}\right) \\
\mathrm{ED}, \mathrm{Mcal} / \mathrm{kg} \mathrm{ms}(D E, \text { Mcal } / k g D M)\left({ }^{3}\right) \\
\mathrm{EM}, \mathrm{Mcal} / \mathrm{kg} \mathrm{ms}(M E, M c a l / k g D M) \\
\mathrm{EM} \% \mathrm{ED}(M E \% D E) .\end{array}$ & $\begin{array}{r}88,6 \\
3,92 \\
3,74 \\
95,5\end{array}$ & $\begin{array}{l}88,3 \\
3,90 \\
3,72 \\
95,3\end{array}$ & $\begin{array}{l}\text { NS } \\
\text { NS } \\
\text { NS } \\
\text { NS }\end{array}$ \\
\hline
\end{tabular}

(1) Porcelets de $30 \mathrm{~kg}$ environ (30 kg liveweight).

(2) Coefficient d'utilisation apparent de l'énergie (Apparent digestibility of energy).

(3) ED : Energie digestible (Digestible energy per kg dry matter).

NS : Effet non significatif (Not significant).

différentes races ou croisements (JENKINSON et al., I967; KEMM et al., I967; SKITSKO et Bowland, I970; KANEv et al., r970; Sharma et al., I971, 1972, I973 : tabl. I; EECKhout et al., I975; FUL,LR et al., I976; PICHA et al., I976). Par ailleurs, au sein d'une même race, Mc CoNNELL et al. (I97I) ne trouvent aucune différence dans l'utilisation digestive de l'énergie entre des animaux maigres et gras. Cette

\section{TABLEAU 2}

Variation de l'utilisation digestive des éléments de la ration et du bilan azoté en fonction du type génétique (') (BOURDON et al., non publié)

Breed differences in apparent digestibility of dietary nutrients and nitrogen retention

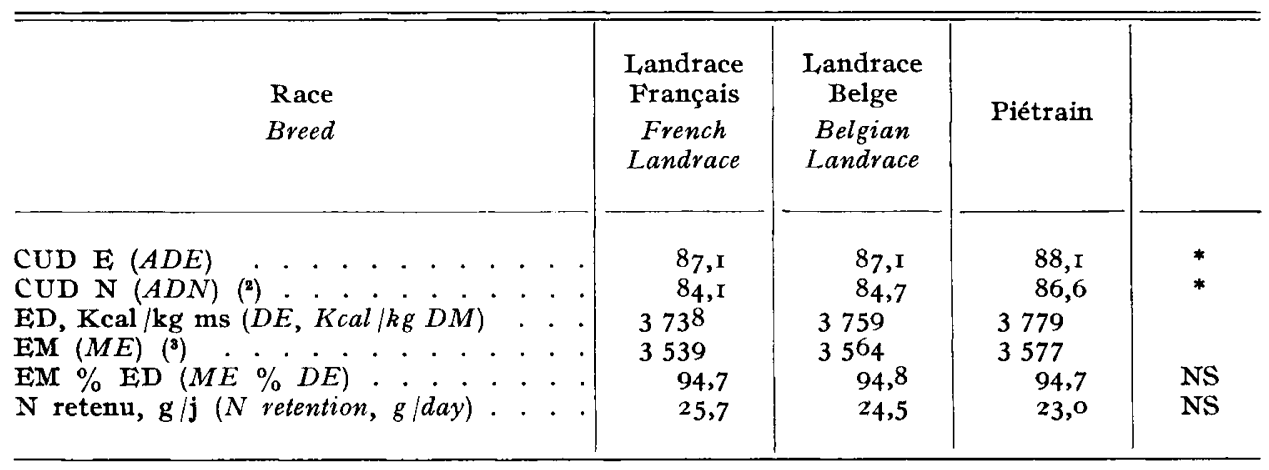

(I) Porcs mâles entiers; résultats moyens à 36,58 et $84 \mathrm{~kg}$ de poids vif (Entire males averaging 36, 58 and $84 \mathrm{~kg}$ liveweight).

(2) Coefficient d'utilisation digestive apparent des matières azotées (Apparent digestibility of nitrogen).

(3) EM : Energie métabolisable corrigée pour un bilan azoté nul (Metabolizable energy corrected for zero nitrogen balance).

- Effet significatif au seuil $\mathrm{P}<0,05$ (Significant at the 0.05 level). 
apparente absence d'effets génétiques sur la digestibilité des nutriments n'est pas pour surprendre, si l'on considère la faible variabilité (de I à 3 p. Ioo) des coefficients d'utilisation digestive apparents.

Dans certains cas, cependant, il a été fait état d'une influence de la race sur 1'utilisation digestive de l'énergie (BowlAND, I962; ANDERson et BowLAND, I967; SkORI et al., I970). Un essai effectué dans notre laboratoire (BouRdon et al., non publié), portant sur la comparaison de porcs mâles entiers Landrace Français, Landrace Belge et Piétrain a fait ressortir une meilleure utilisation digestive des substances énergétiques et azotées chez les animaux de race Piétrain (tab1. 2). Ceci semble confirmé par les observations de EECKHOU'T (I972), concluant à un transit digestif plus lent chez les porcs de Piétrain par rapport à ceux de type Landrace Belge, en relation avec un niveau d'ingestion plus faible. A l'intérieur d'une même race, Mc CoNNEl et al. (I972) observent, mais dans un essai sur trois seulement, que des porcs de type gras utilisent mieux la matière sèche et les matières azotées du régime que ceux choisis pour leur faible état d'engraissement.

Il faut préciser que les variations génétiques de 1'utilisation digestive des nutriments ont gériéralement été mesurées dans une gamme relativement peu étendue de régimes alimentaires, exclusivement de type concentré. Il n'est pas exclu que de telles variations soient plus accentuées dans des conditions d'alimentation plus diversifiées, dans le cas notamment d'utilisation d'aliments encombrants.

\section{2. - Variations de l'utilisation de l'énergie métabolisable}

\section{I. - Pour l'entretien}

Le besoin énergétique pour l'entretien dépend de trois composantes : le métabolisme de base, l'activité physique et le coût du renouvellement des protéines corporelles. Dans le cas de l'animal en croissance, ce besoin est généralement estimé par régression de l'énergie fixée (ou de la production de chaleur) sur l'apport d'énergie métabolisable dans un intervalle de poids donné, ces paramètres étant rapportés au poids métabolique (généralement en $\mathrm{kg}^{3 / 4}$ ). Le besoin d'entretien, en énergie métabolisable, est égal à l'abscisse à l'origine et le rendement de l'utilisation de l'énergie métabolisable pour la croissance à la pente de la droite de régression.

Les travaux de Sharma et al. (I97I) sur porcelets d'un poids vif compris entre I 2 et $30 \mathrm{~kg}$ ont montré que le besoin d'entretien ainsi estimé est plus élevé en race Yorkshire qu'en race Lacombe, soit respectivement $\mathrm{I}_{3} 6 \mathrm{Kcal}$ d'EM par $\mathrm{kg}^{3 / 4}$ contre IIo, en raison probablement d'une activité physique supérieure, bien que l'importance accrue du compartiment musculaire laisse préjuger d'un renouvellement plus intense des protéines (tabl. 3). Par contre, le rendement apparent de l'utilisation de l'EM pour l'entretien n'est pas affecté par le type génétique. Les mêmes auteurs (ShaRma et al., I972) constatent que les porcelets croisés Hampshire $\times$ Yorkshire ont un besoin d'entretien plus faible que ceux de race Yorkshire, mais cette différence n'existe que chez les mâles, les femelles étant en tous points comparables dans les deux types génétiques. KEMM et al. (I967) attribuent à une moindre activité physique la meilleure utilisation métabolique de l'énergie chez des porcs de race locale, comparativement aux animaux Landrace. En revanche, FULLER et al. (I976) ont observé que le besoin énergétique d'entretien, en Kcal $\mathrm{EM} / \mathrm{kg}^{3 / 4}$, chez les porcs croisés Landrace $\times$ (Large White $\times$ Landrace $)$ n'est pas différent de celui trouvé chez les animaux Piétrain aux poids de 30 et $60 \mathrm{~kg}$.

En résumé, la différence de besoin énergétique d'entretien en fonction du type génétique ne semble pas résider dans le rendement de l'utilisation de EM pour 
TABLEAU 3

Variation de l'utilisation de l'énergie métabolisable pour l'entretien et la croissance en fonction du type génétique (') (SнакмA et al., I971, 1972)

Breed differences in ME utilization for maintenance and growth

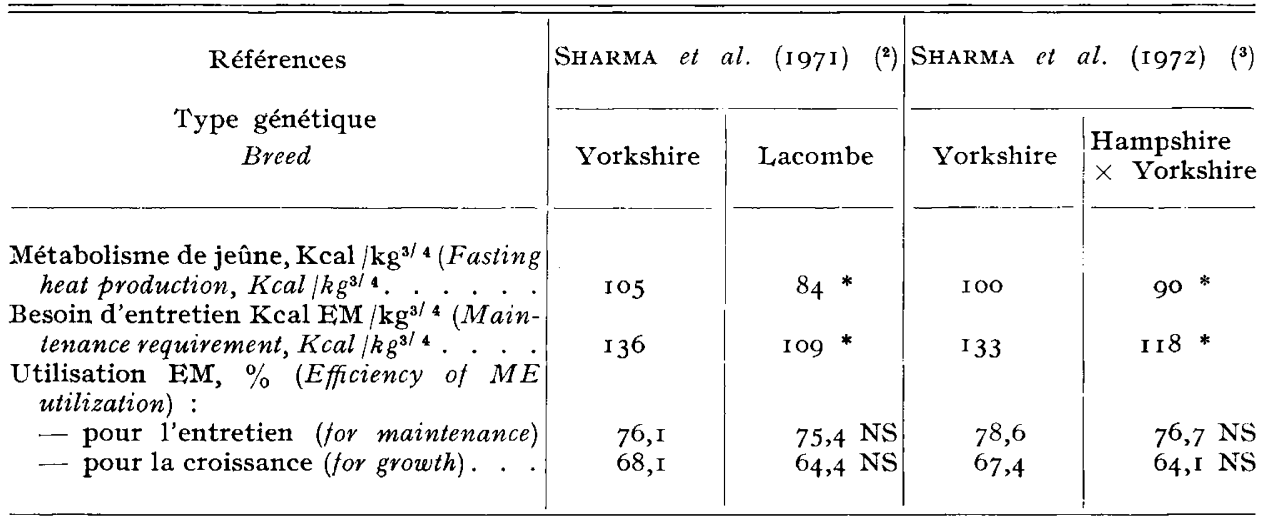

(I) Porcelets d'un poids vif compris entre 12 et $30 \mathrm{~kg}$ (between $\mathrm{I} 2$ and $30 \mathrm{~kg}$ liveweight).

(2) Mâles (Males).

(3) Mâles et femelles (Males and females).

l'entretien mais bien plutôt dans l'intensité du métabolisme de base et l'activité physique des animaux, comme cela a été démontré pour les autres espèces animales, comme les bovins (WEBSTER et al., I976) ou les volailles (WENK et VAN Es, I976). En outre, l'intégration dans l'entretien des dépenses énergétiques liées au renouvellement des protéines corporelles devrait faire apparaître un coût variable selon l'intensité du développement musculaire et donc le type génétique.

\section{2. - Pour les dépôts de protéines et de lipides}

Il est maintenant bien connu que chez le porc, comme chez les autres animaux en croissance, le rendement de l'utilisation de EM pour le dépôt d'énergie sous forme de protéines est nettement plus faible que sous forme de lipides, soit respectivement de 1'ordre de 40-50 p. IOo et 70-80 p. IOo (THORBEK, I975). On pourrait donc s'attendre à une in fluence du type génétique sur le rendement de l'utilisation globale de l'énergie pour la croissance. D'après les résultats disponibles, cela ne paraît pas être le cas (SHARMA et al., I97I, I972; FULLER et al., I976), en raison de la difficulté de mettre en évidence des écarts de rendement relativement faibles.

Si 1'on considère séparément l'utilisation de EM pour le dépôt de protéines et le dépôt de lipides, il n'existe pas non plus de différence connue en fonction du type génétique. En réalité, les dépôts corporels de protéines et de lipides sont la résultante des processus de synthèse et de mobilisation dont il conviendrait de connaître les effets sur le rendement de l'utilisation globale de l'énergie, en relation notamment avec le taux de renouvellement des protéines, qui est nettement supérieur à celui des lipides. Pour ce qui est de la synthèse des protéines au niveau musculaire, les résultats de MosER (I972) sur porcelets provenant de deux lignées, 
maigre et grasse, ne font apparaître aucune différence dans le rapport ARN /ADN. On pense par ailleurs que le développement du tissu adipeux est davantage déterminé par l'activité lipogénique que par la lipolyse, elle-même réglée par les facteurs de mobilisation hypophysaire (revue de HENRY, I977).

\section{3. - Conséquences des variations de la partition de l'énergie fixée sur l'efficacité alimentaire}

Ainsi que 1'a souligné Kielanowski (I976), les dépôts de protéines et de lipides s'accompagnent de coûts d'énergie métabolisable sensiblement comparables par $\mathrm{g}$ de matière organique (environ $\mathrm{I} 2-\mathrm{I} 3 \mathrm{kcal} / \mathrm{g}$ ). Par ailleurs, si 1'on remarque que le dépôt d'un gramme de protéines est associé à une fixation de 3,I g d'eau (Kotarbinska, I969) et que le dépôt d'un gramme de lipides ne s'accompagne guère de fixation d'eau et ne modifie donc pratiquement pas le gain pondéral (VAN Es, I970), il apparaît que les coûts correspondants d'EM par g de tissu musculaire et de dépôt gras sont approximativement dans le rapport $\mathrm{I}: 3$, comme l'ont

\section{TABLEAU 4}

Performances comparées de porcs en croissance selon le type génétique (1)

(d'après SELLIER et al., I977)

Breed differences in growth and feed efficiency traits

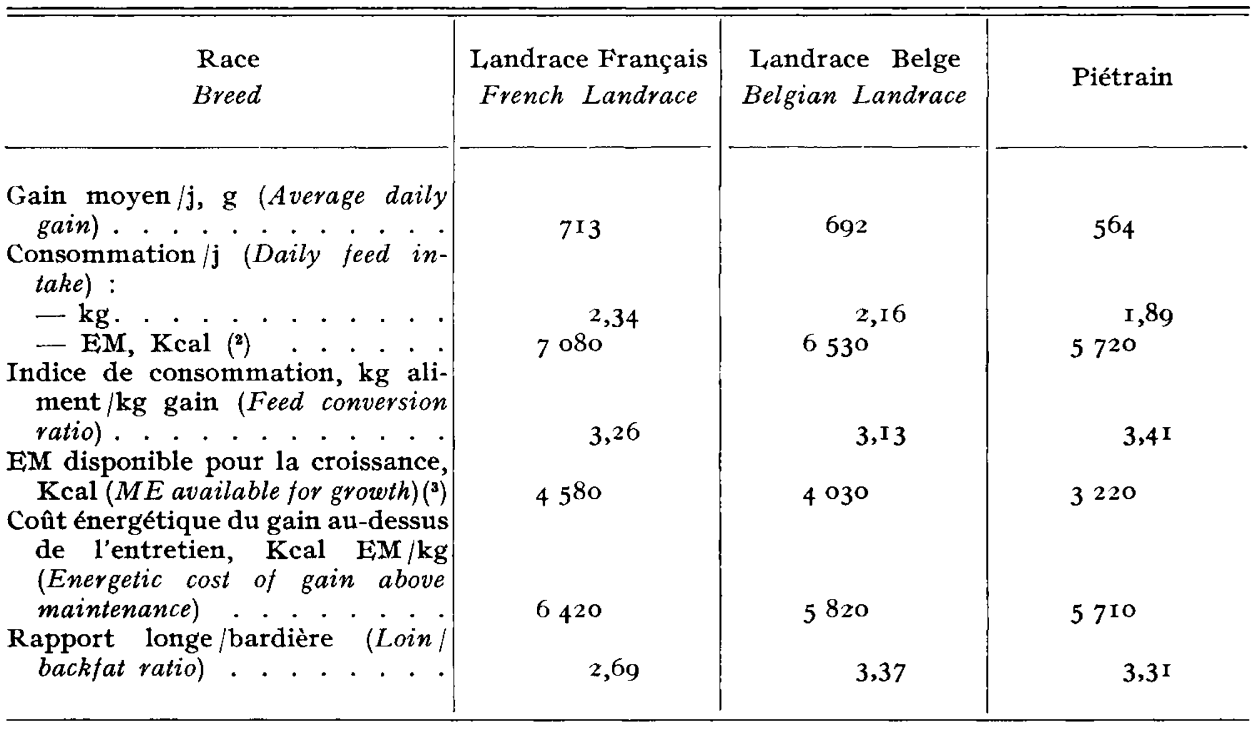

(I) Porcs femelles nourris à volonté entre 27 et $95 \mathrm{~kg}$ de poids vif (Females fed ad lib. between 27 and $95 \mathrm{~kg}$ liveweight).

(2) Valeur énergétique moyenne des régimes : $3025 \mathrm{Kcal} \mathrm{EM} / \mathrm{kg}$ (Average energy value of diets: 3025 Kcal $M E / k g)$.

(3) Après déduction du besoin d'entretien : $115 \mathrm{Kcal} \mathrm{EM} / \mathrm{kg}^{3 / 4}$ au poids vif moyen de $61 \mathrm{~kg}(2500$ Kcal EM/j), estimé dans les conditions normales d'élevage et d'environnement (Assumed maintenance requirement: $I 15 \mathrm{Kcal} M E / \mathrm{kg}^{3 / 4}$ at an average liveweight of $6 \mathrm{r} \mathrm{kg}(2,500 \mathrm{Kcal} M \mathrm{ME} / \mathrm{day})$, by taking into account normal rearing and environmental conditions). 
signalé FOWLER et al. (I976) et KIELANOWSKI (I976). Ceci permet de mettre en relation le rendement de l'utilisation de l'énergie et l'efficacité alimentaire. La quantité d'énergie fixée dans les tissus est en relation avec la fraction de l'énergie métabolisable disponible pour la croissance, après déduction du besoin d'entretien. La partition de cette dernière en protéines et en lipides détermine les quantités respectives de tissus maigres et gras formés, et le gain de poids résultant (KIELANoWSKI, I972). Ainsi, pour un gain de poids donné, une élévation du rapport muscle / graisse entraîne un abaissement du coût énergétique du gain. La quantité d'EM nécessaire au-dessus de l'entretien est plus faible et par voie de conséquence le niveau de consommation d'aliment, correspondant à une amélioration de l'efficacité alimentaire. De la même façon, pour un même niveau d'EM disponible pour la croissance, le gain de poids réalisé est d'autant plus élevé que la proportion d'énergie fixée sous forme de protéines est elle-même plus importante, ce qui a également pour résultat d'améliorer l'efficacité alimentaire. Ceci est illustré par SEL LIIER et al. (I974, I977) qui comparent les performances de porcs à forte musculature (Landrace Belge, Piétrain) et celles d'animaux présentant une conformation normale (Landrace Français). Avec une vitesse de croissance légèrement inférieure à celle des témoins Landrace Français $(692 \mathrm{~g} / \mathrm{j}$ entre 27 et $95 \mathrm{~kg}$ de poids vif contre $7 \mathrm{I} 3)$, les porcs Landrace Belge consomment 8 p. Ioo d'aliment en moins, tandis que l'indice de consommation est réduit de $4 \mathrm{p}$. Ioo (tabl. 4). Dans le cas des animaux Piétrain, également à fort développement musculaire mais à vitesse de croissance lente $(564 \mathrm{~g} / \mathrm{j})$, le niveau d'ingestion est abaissé de $2 \mathrm{I}$ p. Ioo tandis que l'indice de consommation est cette fois accru de $5 \mathrm{p}$. IOo, compte tenu d'une part plus importante de l'entretien dans la dépense énergétique totale et malgré un coût énergétique du gain au-dessus de l'entretien comparable à celui du Landrace Belge.

D'une façon plus générale, comme le suggèrent AILEN et al. (I974, I975) et ALLEN (I976), un développement intense du tissu musculaire par augmentation du nombre de fibres et/ou par une proportion accrue de fibres blanches hyper-trophiques, notamment sous l'effet de la sélection, est nécessairement maintenu plus longtemps et entraîne un développement retardé du tissu adipeux.

\section{II. - Variations génétiques de l'efficacité alimentaire dans des conditions nutritionnelles fixées}

La variabilité génétique s'exprime à l'intérieur des races (et elle peut alors s'envisager sous l'angle polygénique ou monofactoriel), entre races ou lignées (et leurs croisements) et aussi dans le temps, sous l'effet de la sélection pratiquée d'une manière continue par les éleveurs.

\section{r. - Variabilité polygénique}

Il est généralement admis que l'indice de consommation du Porc est un caractère déterminé par un grand nombre de gènes, non identifiés, dont les effets individuels sont faibles relativement à la variabilité totale du caractère. C'est l'hypothèse de base de toutes les études biométriques menées sur le Porc depuis celle de Lush (I936) sur le porc danois. Ces études, du moins en Europe, ont presque toujours porté sur des mesures de consommation alimentaire effectuées dans des 
stations d'épreuve de descendance, avec des conditions de milieu maintenues aussi constantes que possible. Le paramètre majeur recherché est l'héritabilité $\left(h^{2}\right)$, qui indique la part de variation d'origine génétique additive et donc utilisable d'une manière simple par le sélectionneur. Un autre paramètre, dont la signification est moins claire, est 1a. part de variation due à la portée $\left(c^{2}\right)$ qui inclut à la fois des effets de dominance et des effets maternels aussi bien d'origine génétique que dus au milieu. Le tableau 5 montre quelques valeurs de ces deux paramètres dans des populations porcines européennes. L'héritabilité caractérise une population et on peut s'attendre $a$ priori à des variations importantes selon les fréquences géniques aux locus qui déterminent le caractère. Les faibles différences observées, surtout si l'on exclut la plus récente analyse danoise qui semblerait indiquer une tendance réelle à l'épuisement de la variabilité génétique, pourraient donc surprendre (les valeurs extrêmes sont $0, I_{4}$ à 0,56 , proches des valeurs citées par $F_{L_{4} O C K}$ en I970 pour I4 estimées de la bibliographie, qui allaient de 0,12 à 0,59 avec une médiane de $0,3 \mathrm{I})$. L'efficacité alimentaire dans les races européennes paraît être moyennement héritable et elle manifeste également une composante " portée " notable qui peut aller jusqu'à 20 p. Ioo de la variance totale. Dans la plupart des estimées du tableau 5, les effets de l'élevage d'origine sont inclus dans la composante paternelle, ce qui a pour conséquence, bien qu'une part de ces effets soit

\section{TABLEAU 5}

Héritabilité $\left(\mathrm{h}^{2}\right)$ et effet portée $\left(\mathrm{c}^{2}\right)$ de l'indice de consommation mesuré dans les conditions d'une alimentation individuelle en station dans les populations porcines européennes

Heritability $\mathrm{h}^{2}$ and litter effect $\mathrm{c}^{2}$ of feed conversion in some european pig populations: individual feeding in testing stations

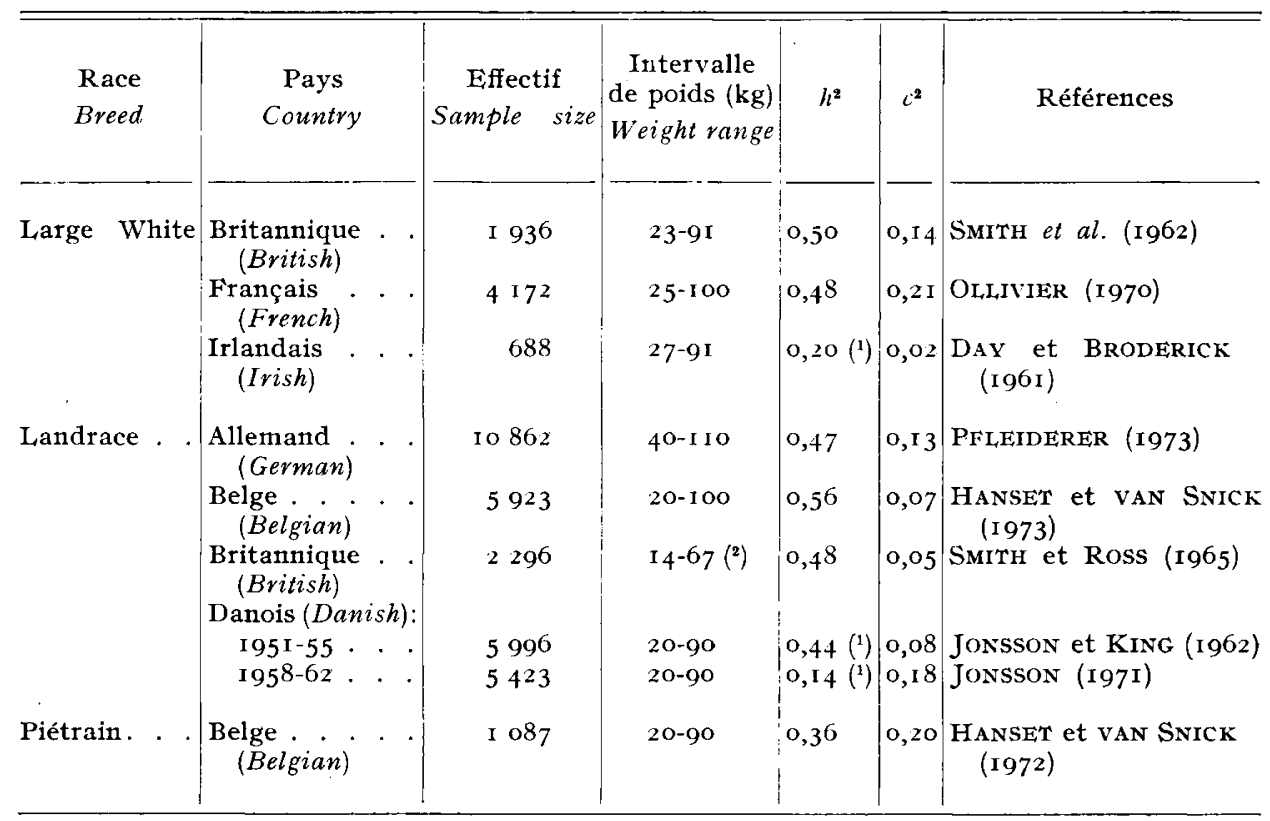

(I) Effet génétique dû à l'élevage exclu (Genetic variance due to farm excluded).

(2) En poids de carcasse (Carcass weight). 
d'origine génétique, de surestimer 1'héritabilité. La part de la variance génétique additive attribuable à l'élevage a été estimée, dans les conditions du Danemark, à 5 p. Ioo par Jonsson (I97I) et 6,9 p. roo par Jonsson et KING (I962), alors qu'en Australie une valeur nettement plus élevée, 9 p. I0o, a été trouvée par Mc PHEF (I974). Dans 1'alternative sélection en ferme ou sélection en station, ces effets sont importants à considérer, comme 1'a montré Mc PHEE (I975), mais l'essentiel est de connaître l'héritabilité de l'indice de consommation dans les conditions de la ferme, qui actuellement n'est pas connue. Quant à la supériorité généralement trouvée de la composante maternelle relativement à la composante paternelle, qui se traduit par une valeur positive de $c^{2}$, le schéma biérarchique sur lequel reposent toutes les estimations du tableau 5 ne permet pas d'en faire l'analyse. Par contre, un schéma dit " diallèle ", qui consiste à accoupler une série de pères à un même groupe de mères rend possible en théorie cette dissociation. Peu d'expériences de ce type ont été réalisées chez le Porc, mais il faut signaler les résultats de LAUPRECHT et al. (I967) qui montrent que l'indice de consommation est sur 4 variables étudiées celle pour laquelle l'interaction père $\times$ mère est la plus élevée (22 p. Ioo de la variance totale). Cela suggère que les facteurs génétiques non maternels (dominance et peut-être épistasie) sont prédominants sur les effets de milieu dans la composante $c^{2}$. D'autres arguments en faveur de cette hypothèse seront considérés lors de l'examen de la variabilité inter-raciale.

Nous disposons de peu d'informations sur la variabilité génétique de critères plus biologiques d'efficacité, tel que, par exemple, le rapport $\mathrm{C} / \mathrm{G}$ (poids de tissu maigre). L'étude de RoBIson et BERRUEcos (I973) suggère, sur des effectiis malheureusement assez restreints, que l'efficacité de la production de tissu maigre serait plus héritable que l'efficacité alimentaire globale, opinion que partagent FOWLER et al. (1976).

\section{2. - Variabilité monofactorielle}

A côté de la variation polygénique, dont la base génétique reste imprécise et ne peut être évaluée que statistiquement, il existe des gènes identifiables dont l'intérêt pour la sélection peut être considérable dans certaines circonstances, comme l'ont montré SMith (I967) et plus récemment MERAT (I975) dans le cas de la Poule. Chez le Porc, le nombre de locus recensés par MíscherLich (I965) était de 20 , et concernait principalement des groupes sanguins. Das revues plus récentes sur des polymorphismes enzymatiques ont été faites par Mc DERMID (I975) et par WIDAR et al. (I975). Ceux-ci ont montré que, sur les I9 locus qu'ils ont examinés dans les races belgas, quatre manifestent un polymorphisme et que sur l'ensemble des données publiées I4 locus polymorphiques ont été trouvés sur les 3 I étudiés.

La mise en évidence d'effets génétiques à un locus particulier se heurte à des problèmes méthodologiques ardus, car il faut d'abord séparer convenablement les effets de milieu et, même si cela a été fait, il reste toujours possible de confondre l'effet pléiotropique du gàne étudié, qui est permanent, avec l'action d'un autre gène étroitement lié au précédent, auquel cas l'effet mis en évidence n'a aucune généralité. Il est donc nécessaire de confronter, pour le même gène, des résultats obtenus dans différentes populations. Les confrontations faites jusqu'à présent ont parfois mis en évidence des discordənces. Ainsi, l'effet du factəur sang uin $\mathrm{M}_{a x}$ sur l'indice de consommation, də l'ordre de o, I3 point, trouvé par BALTZER (I964), n'a pas été confirmé par Schrape (cité par JeNSEn et al., 1968). Las étudas de JENSEN et al. (r968) et de KENNEDY et al. (I973) s'accordent au contraire pour 
montrer que les facteurs de groupes sanguins et les protéines sériques ont peu d'incidence sur l'efficacité alimentaire du porc en croissance, si l'on en juge indirectement par les résultats obtenus sur la vitesse de croissance : chez les premiers auteurs, la part de la variance intra-portée attribuable à 1'ensemble des 16 systèmes étudiés est aux alentours de I p. Ioo (dans deux races), et les seconds n'obtiennent d'effet significatif que pour un facteur de groupe sanguin sur les 26 étudiés.

Il est connu que l'efficacité alimentaire dépend dans une grande mesure de l'état de santé de 1'animal (PlONaIT, I976) et que par ailleurs, dans plusieurs espèces, des relations entre les polymorphismes protéiques et la résistance à certaines maladies ont été prouvées. Dans ce contexte, les relations trouvées par PRzYTulksi et PoRzeczkowska (I976) entre la résistance à la leptospirose et les variants de 1'amylase sérique méritent d'être rapprochés des effets sur la vitesse de croissance trouvés pour ce même locus par BEzEN ko et al. (I97I).

Des résultats récents s'accordent à attribuer un déterminisme monofactoriel récessif au syndrome d'hyperthermie maligne (SHM) déclenché par l'anesthésie à l'halothane : Minkema et al., I976; Orilivier et al. (I975), WebB et Smith (1976). Les incidences de ce gène sur l'efficacité alimentaire ont été étudiées aux PaysBas par EIKELENBOOM et al. (I976) et VERSTEGEN et al. (I976), en alimentation restreinte ou ad libitum. De l'ensemble de ces résultats il ressort que les incidences du SHM sur l'efficacité alimentaire tout comme sur la vitesse de croissance sont minimes. L'effet du gène semble cependant légèrement défavorable, car il entraîne une réduction significative du niveau de consommation en alimentation ad libitum. Les résultats obtenus récemment en France sur des verrats Landrace Belge et Français confirment le faible effet du gène sur les performances d'engraissement (tabl. 6). Comme les effets de ce gène sur le développement musculaire sont par contre très importants (EIKELENBOOM et MinkEMA, I974; MONIN et al., I976), on peut en déduire que les animaux porteurs de cette anomalie, bien que manifes-

\section{TABIEAU 6}

Relaticn entre le syndrome d'hyperthermie maligne (SHM) et les performances individuelles des verrats $(35-85 \mathrm{~kg})$

Relationship between malignant hyperthermia syndrome, MHS, and boar performance-test results over a liveweight range of 35 to $85 \mathrm{~kg}$

\begin{tabular}{|c|c|c|}
\hline $\begin{array}{l}\text { Performance } \\
\text { Trait }\end{array}$ & $\begin{array}{l}\text { Différence (normal }-\mathrm{SHM}) \pm \text { Erreur standard } \\
\text { Difference (normal }-\mathrm{MHS}) \pm \text { Standard error }\end{array}$ & $\begin{array}{l}\text { Test } \mathbf{F} \\
F \text { test }\end{array}$ \\
\hline 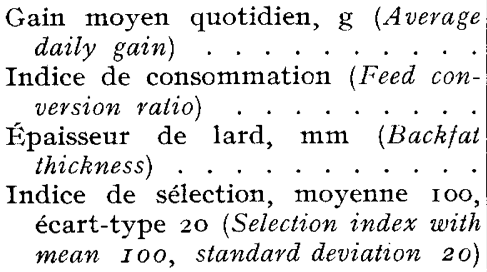 & $\begin{array}{c}\text { I I } \pm \text { I3 } \\
\text { o,or } \pm 0,03 \\
0,8 \pm 0,3\end{array}$ & $\begin{array}{l}\text { NS } \\
\text { NS } \\
P<\text { o, OI } \\
P<\text { o, OI }\end{array}$ \\
\hline
\end{tabular}

Échantillon de 205 verrats, dont 69 SHM, Landrace Belge et Français, contrôlés en I976 (69 MHS and 136 normal Belgian and French Landrace boars). 
tant une efficacité alimentaire globale équivalente à celle des porcs normaux, sont plus efficaces dans la production de tissu maigre, supériorité qui se reflète dans l'indice de sélection du tableau 6 . Ce raisonnement repose cependant sur l'hypothèse d'égalité des compositions corporelles des deux types au début de la période de contrôle, hypothèse qui paraît contredite tant par l'examen visuel (OI,IVIER et al., I976) que par les taux de créatinine plasmatique (ANSAy et OLLIVIER, I978) des deux types d'animaux en début d'engraissement.

Au vu de l'ensemble de ces résultats, une sélection indirecte pour l'indice de consommation en fonction des gènes jusqu'à présent identifiés ne paraît pas pouvoir être recommandée.

\section{3. - Variabilité inter-raciale}

I1 s'agit ici de différences bien connues de longue date et dont il serait trop long de faire une revue détaillée. La comparaison internationale faite récemment sur les principales races européennes par KING et al. (I975) a 1'avantage de donner, grâce à l'utilisation dans plusieurs pays différents d'une même race témoin, le Landrace norvégien en l'occurrence, une image assez précise d'un large éventail de races, après élimination des effets de milieu propres à chaque pays. Les valeurs extrêmes de l'indice de consommation sur les Io races comparées diffèrent de 0,42 point, ce qui représente entre I et 2 écarts-types de la variation intraraciale.

Le choix de la race peut donc en lui-même apporter des gains importants d'efficacité, bien que d'autres critères doivent bien évidemment être pris en compte. Mais la variabilité entre races peut aussi être exploitée par une autre voie qui est le croisement. Comme 1'a montré SELLIER (I976), les gains à espérer du croisement ont une double origine : la complémentarité et l'hétérosis. Le premier effet repose sur l'existence de différences entre races dans les effets maternels, qui se traduisent par des différences entre croisements réciproques. De telles différences ont précisément été mises en évidence pour l'indice de consommation par KuHLERS et al. (I972) - avantage maternel de la race Poland-China sur la race Yorkshire - et par Johnson et al. (I973) et Young et al. (1976) - avantage maternel du porc Yorkshire sur Duroc et Hampshire. Si des différences d'effet maternel existent entre races, il n'est pas exclu qu'elles existent aussi intra-race et qu'elles expliquent en partie le coefficient $c^{2}$ du tableau 5 .

L'hétérosis est beaucoup mieux connu. Une estimation moyenne, établie par SELLIER (1976) sur la base de I5 expériences de croisement entre races publiées entre I949 et I973, est de 3 p. Ioo, ce qui représente un gain de 0,08 point d'indice de consommation. L'une des bases génétiques de l'hétérosis étant le phénomène de dominance associé à des différences de fréquences géniques entre races, ces résultats suggèrent que le déterminisme génétique de l'indice de consommation n'est que partiellement de caractère additif et que le terme $c^{2}$ du tableau 5 résulte en partie d'effets de dominance. Il faut signaler aussi la grande variabilité des estimations d'hétérosis recensées par SELLIER, qui vont de o pour un croisement Duroc $\times$ Yorkshire (Johnson et al., I973) à 0,27 point pour un croisement Piétrain $\times$ Large White (SELIIER et OLIIVIER, I97I). Cette variabilité a des causes à la fois génétiques (distance génétique) et dues au milieu. L'effet maternel génétique, mis en évidence plus haut, peut également, en théorie, manifester de l'hétérosis, les mères " hybrides " pouvant fournir un milieu maternel supérieur à la moyenne de celui fourni par les deux races parentales. Mais de telles différences, peut-être en raison de la difficulté de les mettre en évidence expérimentalement, n'ont pas encore été décelées pour l'indice de consommation. 


\section{TABLEAU 7}

Gains génétiques en indice de consommation Genetic gains in feed conversion

- Lignées sélectionnées (Selection lines)

\begin{tabular}{|c|c|c|c|}
\hline $\begin{array}{l}\text { Conditions de l'expérience } \\
\text { Experimental conditions }\end{array}$ & $\begin{array}{l}\text { Nombre de } \\
\text { générations } \\
\text { Number of } \\
\text { generations }\end{array}$ & $\begin{array}{l}\text { Réponse moyenne } \\
\text { par génération } \\
\text { Average response } \\
\text { per generation }\end{array}$ & Références \\
\hline $\begin{array}{l}\text { - Lignée DUROC : sélection } \\
\text { divergente sur croissance et } \\
\text { efficacité alimentaire (DU- } \\
\text { ROc line: divergent selection } \\
\text { for growth and feed efficiency) } \\
\text { - Lignée LACoMIE : sélection } \\
\text { sur croissance, avec témoin } \\
\text { (LAcomBE line: selected for } \\
\text { growth with control). : } \\
\text { Lignée LANDRACE : sélection } \\
\text { sur croissance et lard avec } \\
\text { témoin (LANDRACE line: } \\
\text { selected for growth and back- } \\
\text { fat, with control) . . . } \\
\text { Lignée svNTIŕTIQUE ou- } \\
\text { verte : sélection sur crois- } \\
\text { sance, lard et efficacité ali- } \\
\text { mentaire, sans témoin (Open } \\
\text { synthetic line, selection for } \\
\text { growth, backfat and feed } \\
\text { efficiency, no control). . . }\end{array}$ & 8 & $\begin{array}{l}-0,027 \pm 0,034 \\
-0,046 \pm 0,036\end{array}$ & $\begin{array}{l}\text { RAHNEFEI,D (1973) } \\
\text { VANGFN (I974) } \\
\text { WEBB et KING (I976) }\end{array}$ \\
\hline
\end{tabular}

- Populations de ferme (Farm populations)

\begin{tabular}{|c|c|c|c|}
\hline $\begin{array}{l}\text { Race } \\
\text { Breed }\end{array}$ & $\begin{array}{c}\text { Période } \\
\text { Time period }\end{array}$ & $\begin{array}{l}\text { Progrès } \\
\text { génétique annuel } \\
\text { Annual genetic } \\
\text { progress }\end{array}$ & References \\
\hline 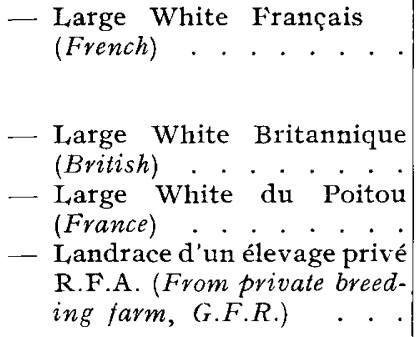 & 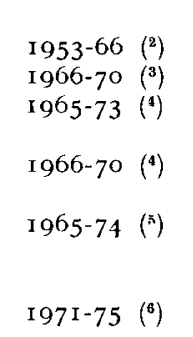 & $\begin{array}{r}-0,079 \pm 0,016 \\
0,033 \pm 0,020 \\
-0,053 \pm 0,009 \\
-0,055 \pm 0,014 \\
-0,037 \pm 0,050 \\
-0,03 \pm 0,009\end{array}$ & $\begin{array}{l}\text { OLLIVIER (I974) } \\
\text { NAVEAU (I97I) } \\
\text { HOUIX et al. (I978) } \\
\text { COOK et al. (I97I) } \\
\text { OLLIVIER (I977) } \\
\text { WILLEKE et RICHTER (I976) }\end{array}$ \\
\hline $\begin{array}{l}\text { (2) Comparaison de cohortes } \\
\text { brogeny of different sire cohorts } \\
\text { (3) Méthode de Smiru (I96 } \\
\text { (4) Troupeau-témoin (Contrc } \\
\text { (5) Accouplements répétés } \\
\text { (6) Comparaison à la moyen }\end{array}$ & $\begin{array}{l}\text { Smith method } \\
\text { erd). } \\
\text { epeat-mating } \\
\text { d'un Herd-Bo }\end{array}$ & omparison with $\mathrm{Her}$ & 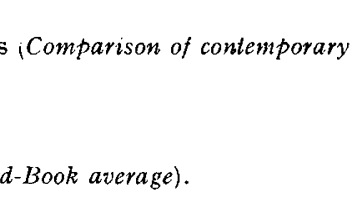 \\
\hline
\end{tabular}




\section{4. - Variabilité temporelle}

L'évolution génétique de l'indice de consommation a pu être étudiée chez le porc grâce d'une part à des expériences de sélection, sur des lignées expérimentales d'effectif limité, et d'autre part à des évaluations de progrès génétique sur des populations animales de ferme (tabl. 7). Les résultats expérimentaux sont dans l'ensemble tout à fait en accord avec les prévisions théoriques qui découlent des estimations de la variabilité polygénique additive. On voit d'autre part que, sur la base des évolutions annuelles les plus favorables, les différences obtenues sur une décennie dans une population sont d'un ordre de grandeur au moins égal à celui des différences extrêmes entre races à un instant donné, telles que celles relevées plus haut dans la comparaison internationale de KING et al. (I975).

Bien que des estimations de progrès génétique suffisamment précises nous manquent avant I950 (revue de FREDEEN, I958), il y a tout lieu de supposer que l'efficacité alimentaire, comme les autres caractères zootechniques du Porc, a évolué très lentement en Europe jusqu'à cette date. Les estimations plus récentes du tableau 7 indiquent que, depuis une quinzaine d'années, cette évolution s'est nettement accélérée dans la plupart des pays, à cause sans doute du développement du contrôle individuel et de l'intensification de la sélection qu'il a permise.

\section{III. - Variations génétiques de l'efficacité alimentaire dans des conditions nutritionnelles variables : Interaction génotype-nutrition}

L'interaction génotype-nutrition s'exprime principalement par les variations de réponse des porcs à des changements dans les niveaux des apports journaliers d'énergie d'une part, de protéines et d'acides aminés d'autre part, suivant que 1'on intervient directement sur les niveaux des apports énergétique et azoté par la voie du rationnement, soit indirectement sur les concentrations en énergie et/ou en protéines (ou acides aminés). Dans ce dernier cas, l'animal a la possibilité de régler lui-même son niveau d'ingestion d'aliment en fonction de l'intensité de ses besoins. Un certain nombre de revues ont été consacrées à ce sujet, dont celles de WATSON (I970), KING (I972), KEMPSTER (I974), GRUMMER (I975).

\section{I. - Variations de réponse en fonction de l'apport énergétique}

\section{I.I. - Influence de la concentration en énergie du régime}

L'élévation de la concentration en énergie du régime chez des porcs de race Large White nourris à volonté entraîne dans l'ensemble une réduction de la quantité moyenne journalière d'aliment consommé, cependant moindre en valeur relative que l'augmentation de la concentration en énergie, de sorte que le niveau d'ingestion énergétique est légèrement accru (HENRY, I969, I974). Il en résulte une légère amélioration de la vitesse de croissance, et surtout une augmentation de l'état d'engraissement des carcasses à l'abattage. Bien entendu, l'indice de consommation est abaissé mais le coût énergétique du gain n'est pratiquement pas modifié, tout 
au moins dans les limites habituelles de variation de la concentration en énergie.

Les variations de réponse des porcs à la concentration en énergie de la ration, selon le type génétique, ont fait 1'objet d'un premier travail de SkITsko et BowLAND (I970). Utilisant un mode d'alimentation semi ad libitum (un repas d'une heure par jour), ces auteurs observent, pour la consommation d'énergie, une interaction entre la race et la valeur énergétique de la ration, mais qui ne se retrouve pas en gain moyen journalier ni en efficacité alimentaire : l'abaissement du niveau d'ingestion énergétique est particulièrement net avec le régime à faible concentration en énergie chez les porcs croisés Duroc $\times$ Yorkshire, de type gras, compa-

\section{TABLEAU 8}

Influence de la concentration en énergie du régime sur les performances de croissance du porc selon le type génétique (1) (SELLIER et al., 1977)

Breed differences in response to variations in dietary energy concentration

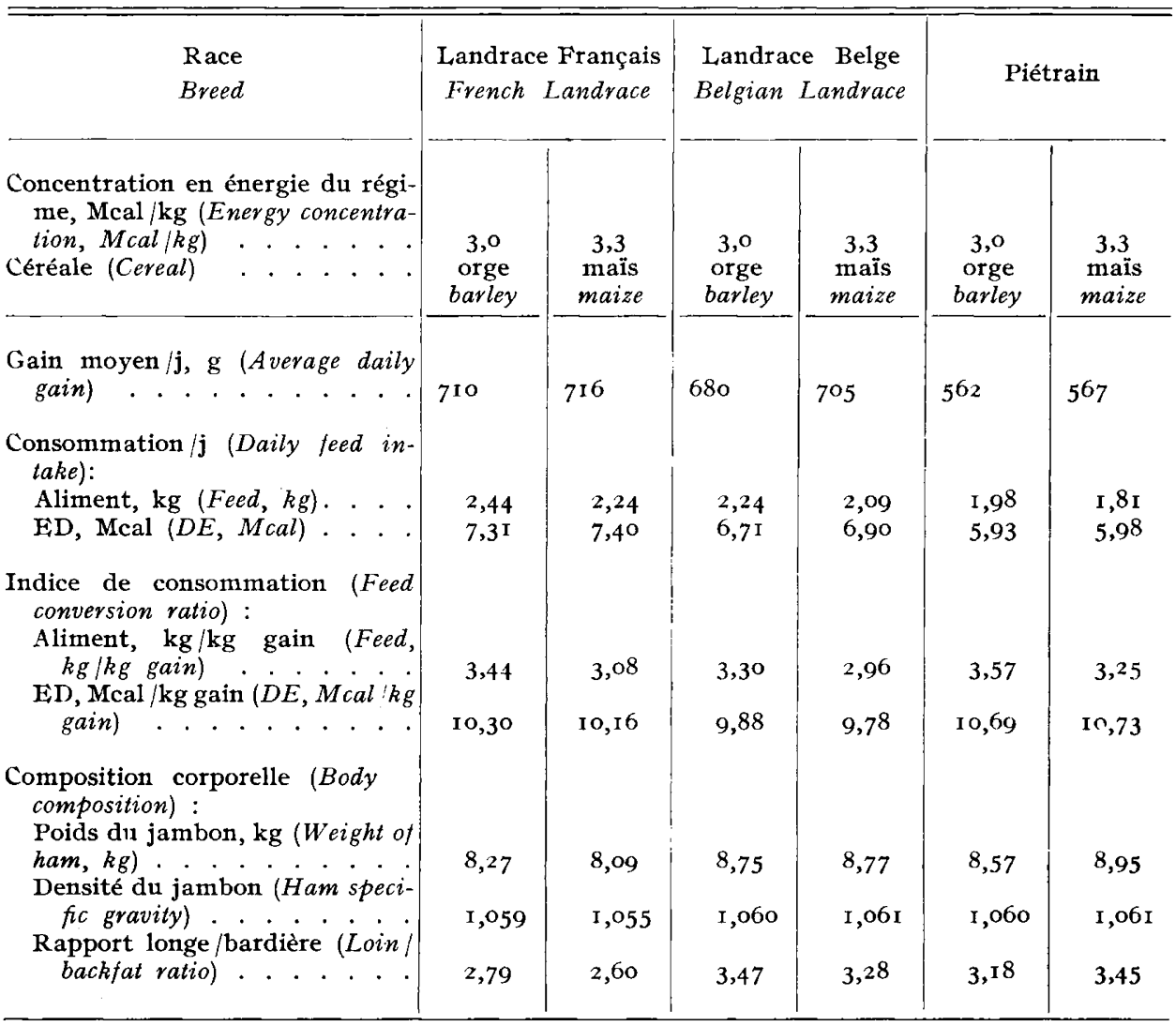

(I) Porcs femelles nourris à volonté entre 27 et $95 \mathrm{~kg}$ de poids vif; régimes renfermant en moyenne respectivement 6I et $58 \mathrm{~g}$ de matières azotées/Mcal F,D avec l'orge et le maïs (Females fed ad lib. between 27 and $9.5 \mathrm{~kg}$ liveweight; $6 \mathrm{I}$ and $58 \mathrm{~g}$ protein /Mcal DE with barley and maize, respectively). 
rativement aux Yorkshire et aux croisés Hampshire $\times$ Yorkshire, plus maigres. Des interactions entre le génotype et la valeur énergétique du régime ont été trouvées plus récemment par SELLIER et al. (I974, I978) sur des femelles nourries à volonté de régimes avec un rapport matières azotées /énergie digestible constant (tab1. 8). Alors que les porcs de race Landrace Français, de type plutôt gras, réagissent à une augmentation de la concentration en énergie du régime de l'ordre de ro p. Ioo (passage d'un régime à base d'orge à un régime à base de maïs) par un accroissement de leur état d'engraissement à $95 \mathrm{~kg}$ de poids vif, les animaux de type Piétrain, à fort développement musculaire, accusent un état d'adiposité plus faible avec le régime le plus riche en énergie, tandis que les porcs Landrace Belge réagissent d'une façon intermédiaire. Toutefois, aucune interaction significative n'est notée pour le gain moyen journalier ni l'indice de consommation, le coût énergétique du gain (Mcal ED/kg) n'étant pas affecté par la concentration en énergie du régime. D'après ces résultats, il semble que les porcs Piétrain, dont la capacité d'ingestion est limitée, augmentent légèrement leur consommation d'énergie digestible, principalement avant $50 \mathrm{~kg}$ de poids vif, et utilisent cet apport supplémentaire d'énergie pour déposer du maigre. Les Landrace Français, au contraire, utilisent l'excès d'énergie pour déposer du gras.

Lors de la comparaison de porcs croisés issus de pères Piétrain et Landrace Français, BoLET et al. (I977) enregistrent des interactions moins prononcées entre le génotype et la concentration en énergie de la ration. La stimulation de la vitesse de croissance consécutive à l'utilisation de régimes à valeur énergétique élevée est un peu plus nette dans le cas des croisés Piétrain, principalement entre 30 et $60 \mathrm{~kg}$ de poids vif, et ceci sans que la composition corporelle soit sensiblement modifiée.

\section{I.2. - Influence du niveau de l'apport énergétique journalier}

L'étude de l'influence du niveau de l'apport énergétique journalier sur les performances de croissance et l'efficacité alimentaire, selon le génotype, l'apport azoté étant maintenu constant, a été effectuée pour la première fois par DAVEY et al. (I969), grâce à la comparaison de lignées maigres et grasses sélectionnées au sein des races Duroc et Yorkshire (tab1. 9).

La réduction de la vitesse de croissance à la suite de l'application d'un niveau restreint d'alimentation représentant $75 \mathrm{p}$. Ioo du niveau témoin est surtout importante dans les lignées Duroc; elle est accompagnée d'une amélioration de l'efficacité alimentaire qui semble plus marquée dans les lignées Yorkshire. Dans tous les cas, ce sont les dépôts gras qui sont le plus affectés par la restriction alimentaire, d'une façon d'ailleurs uniforme dans les lignées maigres et grasses. En ce qui concerne les tissus maigres, l'effet lignée est plus accusé, la lignée maigre étant la plus sévèrement affectée par la réduction de l'apport énergétique, en raison précisément d'un développement musculaire plus intense.

En définitive, les modifications de l'apport énergétique, suivant qu'il s'agit d'un simple contrôle de la concentration en énergie du régime en alimentation à volonté ou d'une restriction imposée de l'apport énergétique journalier, produisent des effets variables selon le type génétique sur le développement musculaire et l'intensité des dépôts gras, ce qui devrait entraîner a fortiori des réponses différentes des performances de croissance et de 1'efficacité alimentaire. En fait, les différences observées sont souvent peu marquées. 
TABLEAU 9

Infuence d'une restriction alimentaive sur les performances de croissance et les dépóts corporels chez le porc selon le type génétique (1) (DAVEY et al., 1969)

Response of different selection lines to restricted feeding

\begin{tabular}{|c|c|c|c|c|c|c|c|c|}
\hline \multirow{3}{*}{$\begin{array}{l}\text { Race }(\text { Breed }) \\
\text { Lignée }(\text { Line }) \\
\end{array}$} & \multicolumn{4}{|c|}{ YORKSHIRE } & \multicolumn{4}{|c|}{ DUROC } \\
\hline & \multicolumn{2}{|c|}{ Grasse (Fat) } & \multicolumn{2}{|c|}{ Maigre (Lean) } & \multicolumn{2}{|c|}{ Grasse (Fat) } & \multicolumn{2}{|c|}{ Maigre (Lean) } \\
\hline & 100 & 75 & IOO & 75 & 100 & 75 & Ioo & 75 \\
\hline 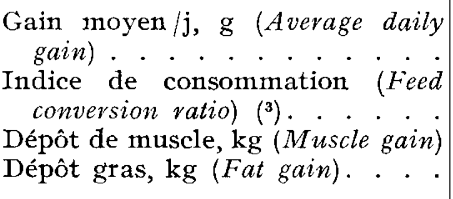 & $\begin{array}{c}604 \\
3,79 \\
23,7 \\
34,4\end{array}$ & $\begin{array}{c}494 \\
3,56 \\
24,8 \\
22,7\end{array}$ & $\begin{array}{l}640 \\
3,77 \\
30,2 \\
28,2\end{array}$ & $\begin{array}{c}54^{2} \\
\\
3,5 \mathrm{I} \\
26,6 \\
18,5\end{array}$ & $\begin{array}{c}596 \\
\\
3,67 \\
21,7 \\
45,0\end{array}$ & $\begin{array}{l}482 \\
\\
3,45 \\
\mathrm{I} 9,3 \\
3 \mathrm{I}, 4\end{array}$ & $\begin{array}{c}712 \\
3,46 \\
28,0 \\
37,0\end{array}$ & $\begin{array}{l}535 \\
\\
3,57 \\
25,6 \\
23,4\end{array}$ \\
\hline
\end{tabular}

(r) Mâles castrés : résultats entre 56 et 224 jours d'âge (Castrated males between 56 and 224 days).

(2) Même apport de matière azotées /jour (Same daily protein intake).

(3) $\mathrm{Kg}$ aliment $/ \mathrm{kg}$ gain (Feed/gain).

\section{2. - Variations de réponse en fonction du rapport matières azotées (ou acides aminés) - énergie}

\section{I. -- En alimentation à volonté}

L'influence du taux global de matières azotées sur les performances de croissance et l'efficacité alimentaire dans un régime à valeur énergétique constante a été le plus souvent confonđue avec le taux d'acide aminé limitant, généralement la lysine, de sorte que dans l'interaction taux azoté $\times$ génotype il y a lieu de tenir compte avant tout de l'équilibre entre les acides aminés indispensables pour qu'une telle interaction ait une signification véritable au plan tant métabolique que nutritionnel.

Il est évident, par ailleurs, que les interactions qui peuvent apparaître entre le taux azoté et le type génétique s'expriment de façon plus ou moins nette selon les différences dans les types de porcs ou les régimes utilisés, et selon le nombre de répétitions, ce qui explique l'apparente divergence des résultats obtenus suivant les auteurs.

Tandis que BowLAND et BERG (I959) n'observent qu'une légère interaction entre le rapport matières azotées-énergie et le type génétique, HALE et SouTHWEL, (I967) rapportent qu'une réduction relativement sévère du taux azoté au-delà de $50 \mathrm{~kg}$ de poids vif produit des effets plus défavorables chez les porcs Duroc que chez ceux de race Hampshire, plus maigres mais à croissance plus lente, notamment pour l'efficacité alimentaire. Se situant dans des conditions extrêmes, portant sur 
la comparaison d'une race améliorée (Large White) et d'une race locale (porc ibérique), ODRIOzoLA et al. (I969) font état d'une nette différenciation de la réponse à une complémentation azotée, l'effet étant favorable uniquement chez les porcs améliorés. A la suite de l'utilisation de régimes riches en protéines, KING (I972) n'observe de son côté aucune interaction significative entre le génotype et le taux azoté pour le pourcentage de muscle dans la carcasse au poids d'abattage de $59 \mathrm{~kg}$. Il en est de même de CunNingham et al. (I973) après une réduction importante du taux de protéines dans la ration à ro p. Ioo avec supplémentation en lysine. Par contre, selon IRVIN et al. (I975), la réduction de l'adiposité observée à la suite de l'élévation du taux de protéines chez les porcs Hampshire n'apparaît pas chez les croisés Yorkshire $\times$ Hampshire, ce qui s'explique par un besoin accru en acides aminés relativement à l'énergie chez les premiers.

Les variations simultanées du taux de protéines et de la concentration en énergie chez des porcs de 4 lignées grasses et maigres sélectionnées au sein des races Yorkshire et Duroc n'ont pas permis à BERESKIN et DAVEY (I975) de mettre en évidence une interaction entre le génotype et le régime, probablement en raisor: des niveaux insuffisamment bas des concentrations tant en protéines qu'en énergie.

Dans 1'étude déjà citée (SELLIER et al., I974, I978), nous avons procédé, sur des porcs femelles des trois races Landrace Français, Landrace Belge et Piétrain, à la comparaison de deux rapports matières azotées-énergie, soit respectivement

\section{TABLEAU IO}

Influence du rapport matières azotées lénergie digestible sur les performances de croissance du porc selon le type génétique (1) (SELLIER et al., I978)

Response in growth traits of different breeds to variations in protein/energy ratio

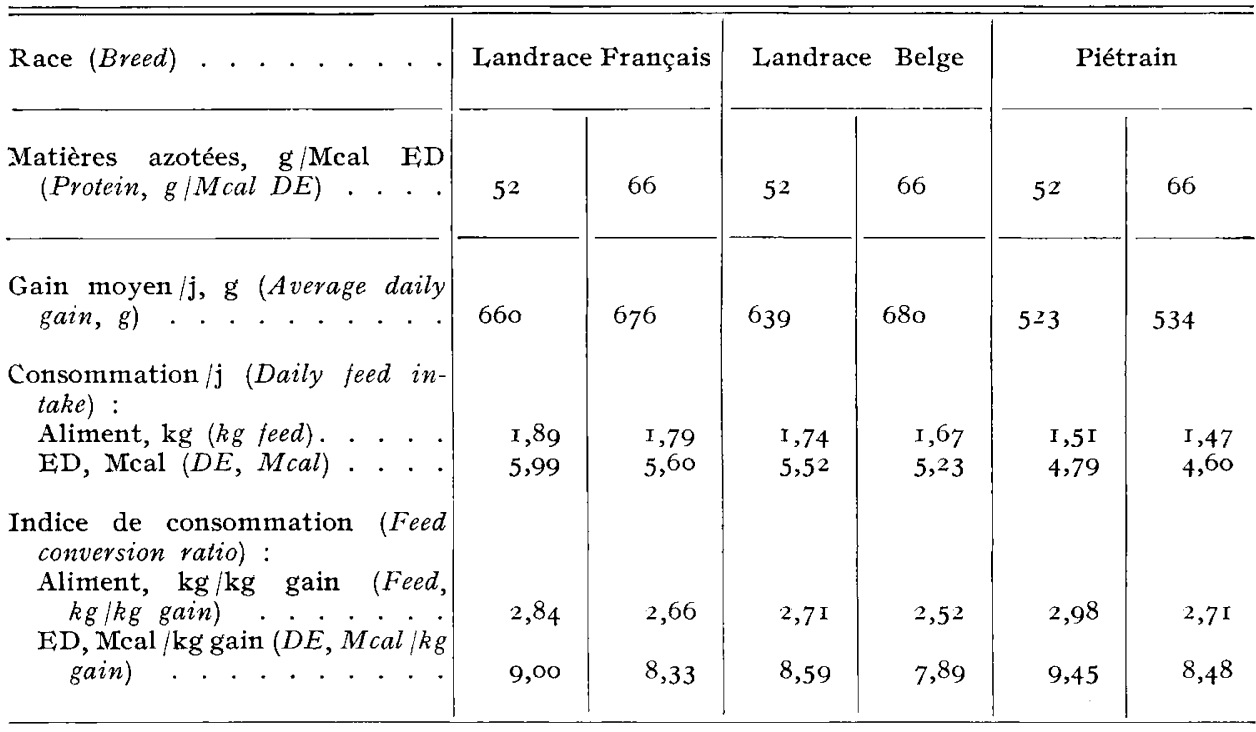

(I) Porcs femelles nourris à volonté; résultats entre 27 et $50 \mathrm{~kg}$ de poids vif. Concentrations moyennes en énergie : 3,17 et 3,1 $3 \mathrm{Mcal} / \mathrm{kg}$ respectivement pour 52 et $66 \mathrm{~g}$ matières azotées/Mcal ED (Females fed ad lib., between 27 and $50 \mathrm{~kg}$ liverveight, average energy content 3.17 and $3.13 \mathrm{Mcal} / \mathrm{kg}$ for 52 and $66 \mathrm{~g}$ protein/ Mcal DE, respectively). 
$52 \mathrm{~g} /$ Mcal ED (correspondant aux recommandations du NRC, r973) et $66 \mathrm{~g}$ (soit $25 \mathrm{p}$. Ioo de plus). L'élévation du taux azoté entre 27 et $50 \mathrm{~kg}$ de poids vif entraîne une amélioration du gain moyen journalier, principalement chez les animaux Landrace Belge, tandis que le même effet favorable est observé dans les troisraces pour l'indice de consommation (tabl. Io). Le maintien d'un taux azoté élevé au-delà de $50 \mathrm{~kg}$ de poids vif provoque au contraire un effet dépressif sur la croissance chez les porcs les moins exigeants en acides aminés, en l'occurrenceles Landrace Français. S'il n'apparaît pas d'interaction significative race $\times$ taux azoté sur les caractéristiques de composition corporelle, l'effet du taux azoté sur le pourcentage de tissus maigres dans la carcasse tend à être plus élevé chez les Landrace Belge (plus exigeants en acides aminés) et les Landrace Français (qui accusent une réduction de leur niveau d'ingestion) que chez les Piétrain. De ces résultats, il ressort que les porcs Landrace Belge (culards à croissance rapide) paraissent plus exigeants en protéines et en lysine (acide aminé limitant primaire) que ceux de type Landrace Français et même Piétrain (culards à croissance lente). Dans le même ordre d'idées, BOLET et al. (I977) soulignent que la réduction du taux azoté qui est généralement recommandée en période de finition entraîne une détérioration plus marquée de l'indice de consommation chez les croisés Piétrain que chez les croisés Landrace Français, en raison d'une exigence plus grande des premiers en acides aminés.

En ce qui concerne plus particulièrement l'interaction entre le taux d'acide aminé limitant et le génotype, les travaux d'EEckhouT et al. (I97I $a, b$ ) sur des porcs à fort développement musculaire (Landrace Belge et Piétrain) nourris à volonté $n$ 'ont pas permis de faire ressortir un effet favorable d'une supplémentation en lysine et en acides aminés soufrés au-delà des taux respectifs de 0,76 et $0,5 \mathrm{I}$ p. Ioo dans une ration renfermant I UF $/ \mathrm{kg}$, soit enviion $3050 \mathrm{Kcal} \mathrm{ED}$. Ceci nous a conduit à conclure (HENRY et al., I976) qu'un apport de lysine de z,5 g/Mcal ED recommandé entre 20 et $50 \mathrm{~kg}$ de poids vif pour la froduction de carcasses maigres convient également pour les types de porcs à fort développement musculaire nourris à volonté. Lors d'une supplémentation en lysine en période de finition (au-delà de $50 \mathrm{~kg}$ de poids vif), BROwN et al. (I973) rapportent des résultats de rétention azotée différents selon le génotype.

\section{2. - En alimentation restreinte}

L'application d'un plan de rationnement en fonction du poids vif permet de mieux contrôler les variations du taux azoté ou d'acides aminés, indépendamment des effets propres de l'équilibre azote-énergie sur le niveau d'ingestion. On sait en effet que l'administration de régimes renfermant un taux suboptimal de protéines (ou d'acides aminés) à des porcs nourris à volonté peut entraîner une stimulation compensatrice de la consommation d'aliment à des degrés cependant variables selon la nature du régime (NOBIET et HENRY, I977). Il en résulte que les différences imposées par le taux d'incorporation dans la ration sont plus ou moins tamponnées par les quantités ingérées quotidiennement, ce qui atténue les écarts observés dans les performances de croissance et l'efficacité alimentaire.

Dans leur étude devenue désormais classique, Davey et Morgan (I969) ont montré que l'élévation du taux de matières azotées de I 2 à $20 \mathrm{p}$. Ioo chez des porcs issus de lignées maigres sélectionnées dans les races Yorkshire et Duroc provoque un accroissement du dépôt des tissus maigres de 31 p. Ioo contre $6 \mathrm{p}$. Ioo seulement dans les lignées grasses (tabl. Ir). Malheureusement, le gaspillage d'aliment signalé par les auteurs n'a pas permis de faire état des effets sur l'indice de consommation. 
TABLEAU II

Influence du taux azoté sur les performances de croissance et les dépóts corporels, selon le type génétique, chez des porcs soumis à un plan de rationnement ${ }^{\left({ }^{1}\right)}$

(DAVEY et MORGAN, 1969)

Influence of protein content on growth and body composition of different selection lines

\begin{tabular}{|c|c|c|c|c|c|c|c|c|}
\hline Race (Breed) . . . . . . . . & \multicolumn{4}{|c|}{ YOR KSHIRE } & \multicolumn{4}{|c|}{ DUROC } \\
\hline Lignée $($ Line $) .. . . . . . . . .$. & Grass & $(F a t)$ & Maigr & (Lean) & Grass & $(F a t)$ & Maigr & (Lean) \\
\hline Matières azotées, \% (Protein). . & I 2 & 20 & 12 & 20 & I 2 & 20 & I 2 & 20 \\
\hline 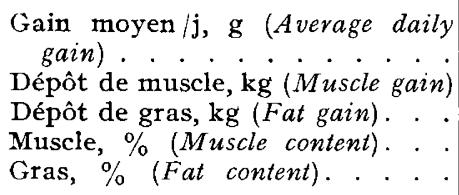 & $\begin{array}{r}356 \\
\text { I } 6,1 \\
\text { I } 2,7 \\
47,5 \\
36,6\end{array}$ & $\begin{array}{r}43 \mathrm{I} \\
\mathrm{I} 8,0 \\
\mathrm{I} 4,3 \\
49,6 \\
34,7\end{array}$ & $\begin{array}{r}325 \\
\text { I } 5,0 \\
9,4 \\
51,6 \\
30,0\end{array}$ & $\begin{array}{r}464 \\
22,6 \\
9,3 \\
59,7 \\
22,6\end{array}$ & $\begin{array}{r}322 \\
\text { I } 3,4 \\
\text { I } 6,4 \\
41,8 \\
43,1\end{array}$ & $\begin{array}{r}379 \\
14,5 \\
16,6 \\
44,1 \\
40,9\end{array}$ & $\begin{array}{l}330 \\
\text { I } 6,5 \\
\text { I I,3 } \\
50,2 \\
32,6\end{array}$ & $\begin{array}{r}455 \\
20,2 \\
9, \mathrm{I} \\
57, \mathrm{I} \\
23,7\end{array}$ \\
\hline
\end{tabular}

(I) Mâles entiers et femelles; résultats moyens entre $5 \mathrm{I}$ et 100 jours d'âge (entre I I et $54 \mathrm{~kg}$ de poids vif). Rationnement en fonction du poids vif (Entire males and females, betreen II and $54 \mathrm{~kg}$ livereight, fed according to weight).

Dans un travail plus récent portant sur les mêmes lignées de porcs, Davey (I976) rapporte que la réduction du taux de protéines de I6 à I I p. Ioo pendant la phase croissance-finition dans des rations à base de maïs entraîne une dépression de croissance plus forte chez les animaux de type maigre (Yorkshire) que chez ceux de type gras (Duroc); à l'intérieur des deux races, c'est la lignée maigre qui bénéficie le plus de l'accroissement du taux de protéines pour la formation des tissus maigres, et a ainsi tendance à présenter une meilleure efficacité alimentaire.

L'amélioration du potentiel de développement musculaire dans les nouveaux types de porcs, ainsi qu'il apparaît à l'examen des données de croissance tissulaire (DESMOUlin et PoMmeret, I974, I975) ou de bilan azoté (Mc CoNNELl et al., I972), a eu pour effet d'élever le niveau des besoins en acides aminés indispensables et en protéines indifférenciées, à la fois en quantité par jour et relativement à l'énergie, compte tenu d'une réduction importante des dépôts gras, donc du besoin énergétique. On explique de la même façon les variations du besoin azoté selon le sexe, le besoin étant plus élevé chez le mâle entier que chez la femelle et a fortiori le mâle castré (BAYley et Summers, ig68; CunNingham et al., I973). Il est possible dans ces conditions, comme le proposent WIESEMÜLLER (I976a, b), OSLAGE et Schulz (1977), de moduler les besoins en acides aminés du porc selon l'intensité de la croissance et la composition du gain en protéines et en acides aminés, ce qui conduit à inclure l'étude de la relation nutrition-génotype dans un schéma plus général d'estimation des besoins nutritionnels en fonction des potentialités différentielles de développenent musculaire et de formation de dépôts gras.

En définitive, l'interaction génotype $\times$ nutrition se traduit avant tout par des différences dans les potentialités de dépôt de tissus maigres et gras selon les 
types génétiques, voire dans le besoin d'entretien. Il resterait cependant à savoir dans quelle mesure le génotype intervient dans le rendement de l'utilisation de l'énergie, comme des acides aminés, pour la réalisation de ces dépôts, en fonction des parts respectives de la synthèse et de la mobilisation, au niveau tant du tissu musculaire que des dépôts gras.

L'étude de cette interaction implique donc surtout une quantification des dépôts tissulaires, directement ou indirectement à partir des données de dissection ou d'analyse chimique corporelle, avec aussi une augmentation souhaitable du nombre d'observations. L'étude de l'adaptation des différents types de porcs au milieu nutritionnel doit être raisonnée d'abord en termes de différences dans la nature et l'importance des dépôts corporels. A un stade plus avancé, il faudra s'attacher à faire ressortir notamment les différences possibles dans les capacités digestives et métaboliques, principalement dans la perspective d'un élargissement de la gamme des aliments utilisables et des systèmes d'exploitation.

\section{Conclusion}

Cette revue a fait apparaître une grande variabilité génétique dans l'espèce porcine pour l'efficacité alimentaire. Cette variabilité, qui résulte principalement de l'importance relative des dépôts de protéines et de lipides, se traduit aussi dans les réponses de l'animal aux variations des apports énergétiques et azotés. Nous nous sommes volontairement limités, faute surtout d'informations suffisantes, à une assez faible étendue de variation : celle des races " améliorées " par rapport à 1a variabilité de l'espèce en généra.l et celle des régim es à base de céréales par rapport à un très large éventail de sources alimentaires utilisables par un animal théoriquement omnivore. Il est certain, toutefois, que les connaissances que nous avons passées en revue, même si leur champ d'application a pu jusqu'à présent paraître restreint, seront de la plus grande utilité dans la recherche d'un animal apte à valoriser au mieux la variété des ressources disponibles, dans des systèmes plus ou moins intensifs.

$$
\text { Reçu pour publication en avril } 1978 \text {. }
$$

\section{Remerciements}

Nous remercions nos collègues H. BEKAER'T et P. M'́rAT qui ont bien voulu lire ce manuscrit.

\section{Summary}

Genetic variations of feed efficiency in the growing pig: Interactions with nutritional conditions

This paper is a review on genetic aspects of feed efficiency. In general, genetic type has little effect on the digestive utilization of nutrients. However, the use of metabolizable energy, either for maintenance or for growth, is largely dependent from genetic type. As regards maintenance requivements, this variability mainly results from differences in basal metabolism and in physical activity. Growth requirements mainly vary as a function of the relative amounts of fat and protein depots. This is reflected through the variability for overall feed conversion. Within breed, feed conversion appears as a polygenic character with medium heritability (from 
o. I 4 to 0.56 in the present european breeds) and is little affected by the individual genes so far detectable. Between breeds, a large variability also exists, which is reflected through a range of 0.42 point in feed conversion found in an international comparison of european breeds and through a highly variable heterosis for single cross, around an average of $3 \mathrm{p}$. 1oo. Finally, in the course of time, large genetic differences may be obtained by selection: a speeding off in genetic progress has been observed recently and, over a period of ten years, genetic gains may equal the difference observed, at a given time, between extreme breeds. Genetic variability also appears in the pig response to changes of diet. When energy intake is modified, through variations in energy concentration with ad lib feeding, no important breed $\times$ diet interaction is observed, as the energy cost of gain is not much changed. If energy is restricted by rationing, however, a marked improvement in feed efficiency is generally obtained, but reverse responses may be obtained in some lines. Raising the protein concentration with ad lib feeding has uniformly favourable effects on feed conversion, except at the end of the fattening period, when this favourable effect only appears in heavily muscled breeds, with high protein and lysin requirements. With restricted feeding, only lean types of pig increase their lean tissue formation as a response to an increased protein intake, feed efficiency itself being not necessarily improved.

\title{
Zusammenfassung
}

\author{
Genetische Variationen der Futterverwertung beim wachsenden Schwein: \\ Wechselwirkung mit den Futterungsbedingungen
}

Die vorliegende Arbeit stellt eine Literaturübersicht über die genetischen Aspekte der Futterverwertung dar. In der Regel wird die scheinbare Verdaulichkeit des Futters wenig durch den genetischen Typ beeinflusst. Dagegen hängt die Verwertung der umsetzbaren Energie für die Erhaltung oder für das Wachstum stark vom genetischen Typ ab. Die Variabilität des Erhaltungsbedarfes wird hauptsächlich durch die Intensität des Grundumsatzes und die körperliche Aktivität der Tiere bedingt. Die Schwankung der Wachstumsbedarfes ist vor allem vom relativen Umfang des Protein - und Fettansatzes abhängig. Diese genetische Variabilität wird in der Gesamtfutterverwertung wiedergespiegelt. Innerhalb der Rasse erscheint die Futterverwertung als ein polygener, wenig von den individuell erkennbaren Genen abhängiger Charakter mit mittlerer Heritabilität (o,I 4-0,56 in den zur Zeit bestehenden europäischen Rassen). Zwischen den Rassen drückt sich diese Variabilität durch einen Unterschied von 0,42 Punkt zwischen den extremen europäischen Rassen und einen Heterosiseffekt von 3 p. Ioo im Durchschnitt bei der einmaligen Kreuzung aus. Schliesslich kann die Selektion im Laufe der Zeit zu grossen genetischen Unterschieden führen : eine Beschleunigung des Zuchtfortschrittes wird seit ca. I 5 Jahren festgestellt und die über eine Periode von io Jahren beobachteten Fortschritte können dem zu einem bestimmten Zeitpunkt ermittelten Unterschied zwischen den extremen Rassen gleichen. Darüber hinaus spiegelt sich die genetische Variabilität in die Antwort des Schweines auf veränderungen der Futterzufuhr wieder. Die Veränderung der Energiezufuhr durch eine schwankende Energiekonzentration in einer ad-libitum-Fütterung führt nicht zu einer unterschiedlichen rassenbedingten Antwort in der Futterverwertung, da der Energieaufwand für die Gewichtzunahme unverändert bleibt. Wird die Energiezufuhr durch Futterbeschränkung vermindert, so wird die Futterverwertung deutlicher verbessert, aber bei bestimmten Tierlinien wird ein umgekehrtes Ergebnis erreicht. Eine Erhöhung des Stickstoffgehaltes in einer ad-libitum-Fütterung bewirkt eine allgemeine Verbesserung der Futterverwertung, abgesehen vcn der Mastendperiode, wo diese günstige Wirkung nur bei den starkbemuskelten Rassen höherem Protein- und Lysinbedarf erscheint. Die Erhöhung der Protein-zufuhr in einer beschränkter Fütterung führt zu einer Steigerung des Fleischansatzes aber nur bei den Rassen mit höherem Fleischanteil, und das wird nicht unbedingt von einer verbesserung der Futterverwertung begleitet.

\section{Références bibliographiques}

AlLEN C. E., 1976. Cellularity of adipose tissue in meat animals. Fed. Proc., 35, 2302-2307. AlLen C. E., Thompson E. H., Hegarty P. V. J., 1974. Physiological maturity of muscle and adipose cells in meat animals. Proc. 27th Annual Reciprocal Meat Conference of the American Meat Science Association 8-27, Nat. Livestock and Meat Board, Chicago (Ill.). 
Allen C. E., Hegarty P. V. J., Etrherton T. D., Aberle E. D., 1975. Biological interaction of muscle and adipose tissues. Proc. 28 th Annual Reciprocal Meat Conference of the American Meat Science Association, 202-2 I3, Nat. Livestock and Meat Board, Chicago (Ill.).

ANDERSON G. H., BOWLAND J. P., I967. Lysine and fat supplementation of weanling pig diets. Can. J. Anim. Sci., 47, 47-55.

Ansay M., OlLivier L., I978. Créatinine plasmatique et susceptibilité du porc au syndrome d'hyperthermie maligne. Ann. Génét. Sél. anim., 10, 9-I6.

BALTZER J., I964. Untersüchungen über das Bestehen von Beziehungen zwischen Blutgruppenfaktoren und Daten des Schlachtkörperwertes und der Mastleistung des Schweines. Züchtungskunde, 36, 317-326.

BAyley H. S., Summers J. D., I968. Effect of protein level and lysine and methionine supplementation on the performance of growing pigs: response of different sexes and strains of pigs. Can. J. Anim. Sci., 48, 18I-I88.

BERESKIN B., DAVEy R. J., I975. Breed, line, sex and diet effects and interactions in swine carcass traits. J. Anim. Sci., 42, 43-5I.

Bezenko S. P., Terentiyeva A. S., Kabanov V. D., Chernuschenko V. K., Budnikova A. V., I97I. Genetical characteristics of the Large white swine breed pertaining to erythrocytal antigens and serum proteins and their relation to certain economically valuable characters (Russe). Genetika, 7, 4, 88-94.

BOLET G., Desmoulin B., Seiliter P., HENRY Y., i 977 . Interactions entre type génétique, sexe et conditions nutritionnelles chez le porc en croissance. Journées Rech. Porcine en France, 79-84, I.N.R.A.-I.T.P. éd., Paris.

Bourdon D., Desloges L., Henry Y. (Résultats non publiés).

Bowland J. P., r96z. Electronic computation of growing and finishing rations for pigs to meet U.S. N.R.C. (I959) nutrient requirements with and without a margin of safety. Canad. J. Anim. Sci., 42, I91-202.

BOWLAND J. P., BERG R. T., I959. Influence of strain and sex on the relationship of protein to energy in the rations of growing and finishing bacon pigs. Can. J. Anim. Sci., 39, IO2-II4.

BRODERICK T., I960. Genetic aspects of pedigree Irish Large white pigs. $J$. Dept. Agric., Ireland, 56, I3-55.

Brown H. D., HaRmon B. G., Jensein A. H., I973. Lysine requirement of the finishing pig for maximum rate of gain and efficiency. J. Anim. Sci., 37, 708-7 I 2.

COOK G. L., SMITH D. H., STEANE D. E., I97I. The progress and penetration of the accreditation scheme in Britain, I966-1970. I0 Congrès intern. de Zootech., Versailles, 17-23 juillet.

Cunningham P. J., Socha T. E., Peo E. R., Mandigo R. W., I973. Gain, feed conversion and carcass traits of swine under two nutritional regimes. J. Anim. Sci., 37, 75-8o.

DAvey R. J., 1976. Growth and carcass characteristics of high-and low-fat swine fed diets varying in protein and lysine content. J. Anim. Sci., 43, 598-605.

DAvey R. J., MORGan D. P., I969. Protein effect on growth and carcass composition of swine selected for high and low fatness. J. Anim. Sci., 28, 83 I-836.

Davey R. J., Morgan D. P., Kincaid C. M., 1969. Response of swine selected for high and low fatness to a difference in dietary energy intake. J. Anim. Sci., 28, 197-203.

DAy W. R., Broderick T., I96I. Some genetic aspects of food utilisation in pigs. J. Dept. Agric. Ireland, 57, 3-I4.

Desmoulin B., Pommeret P., I974. Références de composition anatomique et critères de classification des carcasses de porcs femelles des types Landrace Français, Landrace Belge et Piétrain. Journées Rech. Porcine en France, $221-232$, I.N.R.A.-I.T.P. éd., Paris.

Desmoulin B., Pommere't P., I975. Évolution de la composition anatomique des porcs femelles des types Landrace Français, Landrace Belge et Piétrain : conséquences sur les méthodes d'orientation des productions. J. Rech. Porcine en France, I 79-I94, I.N.R.A.-I.T.P. éd., Paris.

Dickerson G. E., Grimes J. C., I947. Effectiveness of selection for efficiency of gain in Duroc swine. J. Anim. Sci., 6, 265-287.

EECKHOUT W., I972. Vitesse de passage de granulés et de farine à travers le tube gastro-intestinal des porcs Landrace Belge et Piétrain. Rev. Agric., 25, 42 I-434.

Eeckhout W., Bekaert H., Casteels M., Torreele G., Buysse F., i97i. L'addition de lysine et de méthionine à une farine pour porcs de boucherie distribuée sèche et ad libitum à des animaux de race Landrace Beige et de race Piétrain. I. Influence sur les résultats de croissance. II. Influence sur la qualité de la carcasse. Rev. Agric., 24, 63 I-657, 77 I-790.

EECKHOUT W., BEKAERT H., I975. Le métabolisme de l'azote et la digestibilité des aliments chez des porcs hybrides Thornbers et des porcs Landrace Belge. Rev. Agric., 28, 813-827. 
Eirkelenboom G., Minkema D., 1974. Prediction of pale, soft, exudative muscle with a nonlethal test for the halothane-induced malignant hyperthermia syndrome. Neth. J. Vet. Sci., 99, $42 \mathrm{I}-426$.

Eikelenboom G., Minkema D., van El,Dik P., I976. The application of the halothane-test. Differences in production characteristics between pigs qualified as reactors (MHS susceptible) and non-reactors. In Proc. 3rd intern. Conf. on Prod. Disease in Farm Animals, 183-187. Pudoc. Wageningen.

FLOCK D., 1970. Genetic parameters of German Landrace pigs estimated from different relationships. J. Anim. Sci., 30, 839-843.

Fowler V. R., Bichard M., PEase A., 1976. Objectives in pig breeding. Anim. Prod., 23, $365-387$.

Fredeen H. T., 1958. Selection and swine improvement. Anim. Breed. Abstr., 26, 229-24 I.

Fulifer M. F., Weister A. J. F., Mc Pherson R. M., SMith J. S., i976. Comparative aspects of the energy metabolism of Piétrain and Large White $\times$ Landrace pigs during growth. In M. VERMOREL, Energy metabolism of farm animals, E.A.A.P. Publ. $\mathrm{n}^{\circ}$ I9, I77-I 80 , G. de Bussac éd. Clermont-Ferrand.

GRUMMER R. H., 1975. Genetic variation in nutritional requirements of swine. The effect of genetic variance on nutritional requirements of animals, I I 3-I 23, Nat. Acad. Sci., Washington D.C.

HALE O. M., SOUTHWELL B. L., I 967. Differences in swine performance and carcass characteristics because of dietary protein level, sex and breed. J. Anim. Sci., 26, 34 I-344.

HANSET R., VAN SNICK G., I972. Les paramètres génétiques des caractères d'engraissement et de carcasse chez le porc de Piétrain. Ann. Génét. Sél. anim., 4, 45I-467.

HANSET R., VAN SNICK G., I973. Les paramètres génétiques des caractères d'engraissement et de carcasse chez le porc Iandrace Belge. Ann. Génét. Sél. anim., 5, 369-379.

HENRY Y., I 969 . Effets nutritionnels de l'incorporation de cellulose purifiée dans le régime du Porc en croissance-finition. II. Influence sur les performances de croissance et la composition corporelle. Ann. Zootech., 18, 37x-384.

HENRY Y., I974. Incorporation de proportions variables de matières grasses (huile d'arachide) dans le régime du Porc en croissance-finition, en relation avec le taux de matières azotées. II. Influence sur les performances de croissance et la composition corporelle. Ann. Zootech., 23, $37 \mathrm{I}-384$

HENRY Y., I977. Développement morphologique et métabolique du tissu adipeux chez le porc : influence de la sélection, de l'alimentation et du mode d'élevage. Ann. Biol. anim. Bioch. Biophys., 17, 923-952.

HENRY Y., PION R., RERAT A., I976. Protein supply for pigs and possibilities of reducing protein feeding standards. Wld. Rev. Anim. Prod, 12, 9-32.

Hourx Y., Dando P., Sel.lier P., I978. Estimation, à l'aide d'une lignée-témoin, de l'évolution génétique des caractères d'engraissement et de carcasse du porc Large White en France de I 965 à 1973. Ann. Génét. Sél. anim. (à paraître).

Irvin K. M., Swiger L. A., Mahan D. C., 1975. Influence of dietary protein level on swine with different growth capabilities. J. Anim. Sci., 41, I031-1038.

Jenkinson G. M., Young L. G., AshTON G. C., 1967. Energy metabolism and body composition of weanling pigs. Can. J. Anim. Sci., 47, $217-226$.

JENSEN E. L., SMITH C., BAKER L. N., Cox D. F., ig68. Quantitative studies on blood group and serum protein systems in pigs. II. Effects on production and reproduction. J. Anim. Sci., 27, $856-862$.

Johnson R. K., Omtvedt I. T., Walters L. E., I973. Evaluation of purebreds and two-breed crosses in swine: feedlot performance and carcass merit. J. Anim. Sci., 37, 18-26.

Jonsson P., I97I. Population parameter estimates of the Danish Landrace pig. Acta Agric. Scand., 21, I I-I 6.

Jonsson P., KING J. W. B., r96z. Sources of variation in Danish Landrace pigs at progenytesting stations. Acta Agric. Scand., 12, 68-80.

Kanev M., Panajotov P., Angelov I., i97o. Digestibility of feeds and $\mathrm{N}$ balance in pigs of different breeds (en bulgare). Zivotnovodni Nauki, 7, 35-39.

KEMM E. H., Pieterse P. J. S., Lesch S. F., i967. A study of feed utilization in two extreme types of pigs. S. Af. Tydskr. Landbouwet., 10, 997-1003.

KEMPSTER A. J., I974. Genotype $\times$ environment interactions in pigs. I er Congrès mondial de génétique appliquée à l'élevage, $873-884$, Madrid. 
Kennedy B. W., Moxley J. E., SAISON R., 1973. Some relationships between blood group factors and economic traits in swine. Can. J. Anim. Sci., 53, 389-397.

KIELANowski J., 1972. Energy requirements of the growing pig. In D. J. A. ColE, Pig Production, r83-20r, Butterworths, London.

KIELANOWSKI J., I976. Utilization of energy and protein by growing animals. E.E.C. Colloquium on feeding efficiency and interaction between genotype and nutrition in growing animals, I.N.R.A., Theix, France.

KING J. W. B., I972. The interaction of genotype and environment in pig production. In D. J. A. CoLE, Pig Production, 21-36, Butterworths, London.

King J. W. B., Curran M. K., Standal N., Power P., Heanfy I. H., Kalimeit E., Schröder J., Madala K., Kangasniehi R., Walstra P., I975. An international comparison of pig breeds using a common control stock. Livest. Prod. Sci., 2, 367-379.

KOTARBINSKA M., I969. Investigations into the energy metabolism of growing pigs. Instytut Zootechniki, Wydawniotwa Wlasne $\mathrm{n}^{0} 238$, pp. 68, Wroclaw.

KUHLERS D. L., ChAPMAN A. B., FIRST N. L., I972. Estimates of genotype-environment interactions in production and carcass traits in swine. J. Anim. Sci., 35, I, I-7.

Lauprech'T D., Flock D., Hinkermann K., 1967. Diallele Paarungen beim Schwein. Z. Tierzucht. Zücht. Biol.,83, 178-189.

Lush J. L., 1936. Genetic aspects of the Danish system of progeny-testing swine. Iowa Agr. Exp. Sta. Res. Bull., no 204.

Mc ConNei. J. C., BARTh K. M., Grippin S. A., I97I. Nutrient digestibility and nitrogen metabolism studies at different stages of growth with fat and lean type swine fed two levels of protein. J. Anim. Sci., 32, 654-657.

Mc Conneli J. C., Barti K. M., Grifin S. A., 1972. Nitrogen metabolism at three stages of development and its relationship to measurements of carcass composition in fat and lean type swine. J. Anim. Sci., 35, 556-56o.

Mc Dermid E. M., AGar N. S., Chai C. K., I975. Electrophoretic variation of red cell enzyme systems in farm animals. Anim. Blood Grps biochem. Genet., 6, I27-I 74 .

Mc PHEE C. P., 1974. An analysis of variation in performance traits of Large White and Landrace boars tested in the Queensland pig testing station. Aust. J. exp. Agric. Anim. Husb., 14, 5-I I.

Mc PHEE C. P., I975. A comparison of farm and station performance testing of boars. Anim. Prod., 20, 243-248.

MERAT P., I975. Indirect selection in poultry breeding with special reference to single genes. Ann. Génét. Sél. anim., 7, 449-460.

Minkema D., EIKElendoom G., van Eidik P., 1976. Inheritance of M.H.S.-susceptibility in pigs. In Proc. 3 rd intern. Cont. on Prod. Disease in Farm Animals, 203-205. Pudoc, Wageningen.

MitsCHERLICH E., I965. Genetische beziehungen zwischen Figenschaften des Blutes und Leistungmerkmalen bei verschiedenen Haustierarten. Züchtungskunde, 37, 375-387.

Monin G., OLIIVIER L., SELLIER P., I976. Etude du syndrome d'hyperthermie maligne chez le porc de Piétrain. Journées Rech. Porcine en France, 229-238. I.N.R.A.-I.T.P. éd., Paris.

MOSER B. D., I972. The effect of genetic line, sex and source and level of protein on muscle RNA-DNA in the pig. Diss. Abstr. Int., 33, 2423B.

National Research Council, I973. Nutritient requirements of swine, 56 p. Nat. Acad. Sci., Washington D.C.

NAvEAU J., I97I. Le progrès génétique dans les troupeaux de sélection de I966 à I970. Bulletin de l'Institut technique du Porc, 3, I3-г6.

NOBlET J., HENRy Y., I 977. Conséquences d'une réduction du taux de matières azotées sur le niveau de consommation et les performances de croissance, chez le porc, selon l'équilibre en acides aminés et la concentration en énergie du régime. Ann. Zootech., 26, 379-394.

Odriozola M., DE ZuZuarregui J., Sierra dE Castro M., I969. Estabulación de cerdos Ibericos, Madrid.

OLIIVIER L., I970. L'épreuve de la descendance chez le porc Large White Français de I953 à r966. I. Analyse de la variation. Ann. Génét. Sél. anim., 2, 31 I-324.

OLLIVIER L., I974. L'épreuve de la descendance chéz le Porc Large White français de I953 à I966. III. Progrès génétique. Ann. Génét. Sél. anim., 6, 477-492.

OLLIVIER L., I977. Dix ans d'une expérience de sélection individuelle sur des verrats utilisés en insémination artificielle. I. Réponses observées sur des caractères de croissance, de carcasse et de qualité de viande. Ann. Génét. Sél. anim., 9, 353-377. 
Ollivier L., Sellier P., Monin G., I975. Déterminisme génétique du syndrome d'hyperthermie maligne chez le Porc de Piétrain. Ann. Génét. Sél. anim., 7, I 59-166.

Olifivier L., SEl,Lier P., Monin G., 1976. Frequency of the malignant hyperthermia syndrome (MHS) in some french pig populations: preliminary results. In Proc. $3 r d$ intern. Cont. on Prod. Disease in Farm Animals, 208-210, Pudoc, Wageningen.

Oslage H. J., Schulz E., I977. Aminosaüreansatz in verschiedenen Organen und in Gesamtkörper wachsender Schweine sowie Ableitungen zum Aminosaürenbedarf. Vth Internat. Symp. on Amino Acids, Budapest.

Pilfiderer U. E., 1973. Genetische Parameter der wichtigsten Mastleistungs- und Schlachtkörpermerkmale aus der Stationsprufung von Schweinen der Deutschen Landrasse. I. Heritabilitätsschätzungen. Züchtungskunde, 45, 2 I 5-223.

Picha J., OrLik K., Pichova D., Franc C., I976. Protein conversion in growing pigs according to sex and breed (en tchèque). Zivocisna vyroba, 21, 25-32.

Plonais H., i976. Factors affecting feed conversion under practical farm conditions. Pathology. $27^{\mathrm{e}}$ Réunion annuelle de la Féd. europ. Zootech., Zurich, 23-26 août.

Przytulski I., Porzeczkowska D., I976. Polymorphism of blood serum amylase and leptospirosis of pigs of Large White Polish breed. Theoret. Appl. Genet., 48, 237-242.

RAHNEFELD G. W., I973. Mass selection for postweaning growth in swine. III. Correlated response in weaning weight and feed efficiency to recurrent selection for postweaning average daily gain in swine. Can. J. anim. Sci., 53, r73-1 78.

RoBison O. W., I972. The role of maternal effects in animal breeding. V. Maternal effects in swine. J. Anim. Sci., 35, I303-1 315.

Robison O. W., BERRUECos J. M., I973. Feed efficiency in swine. I. A comparison of measurement periods and methods of expressing feed efficiency. $J$. Anim. Sci., 37, 643-649.

Selilier P., i970. Hétérosis et croisement chez le Porc. Ann. Génét. Sél. anim., 2, i 45-207.

Sellier P., 1976. The basis of crossbreeding in pigs. A review. Livest. Prod. Sci, 3, $203-226$.

Selifier P., Olifivier I., I97I. Résultats d'une expérience de croisement Piétrain $\times$ Large White. I. Performances d'engraissement et d'abattage. In Journées Rech. Porcine en France, I2-22. I.N.R.A.-I.T.P. éd., Paris.

Selirer P., Houix Y., Desmoulin B., Henry Y., I974. Premières observations sur la relation entre conditions nutritionnelles et type génétique chez des porcs femelles. In Journées Rech. Porcine en France, 209-z19, I.N.R.A.-I.T.P. éd., Paris.

Seliter P., BOLET G., Henry Y., Desmoul, milieu nutritionnel chez le Porc en croissance. I. Comparaison de femelles des races pures Landrace Français, Landrace Belge et Piétrain en relation avec le régime alimentaire. Ann. Génét. Sél. anim. (sous presse).

Sharma V. D., Young L. G., Smith G. C., I97I. Energy utilization by the Lacombe and Yorkshire breeds of pig. Can J.Anim. Sci., 51, 761-770.

Sharma V. D., Young I. G., Smith G. C., SaIson R., I972. Effects of crossbreeding and sex on energy requirements and utilization by young pigs. Can. J. Anim. Sci., 52, 75I-759.

Sharma V. D., Young I. G., Brown R. G., Buchanan-Smith J., Smith G. C., I973. Effects of frequency of feeding on energy metabolism and body composition of young pigs. Can. J. Anim. Sci., 53, I 57-I64.

Skitsko P. J., Bowland J. P., I970. Performance of gilts and barrows from three breeding groups marketed at three liveweights when offered diets containing two levels of digestible energy for a limited period per day. Can. J. anim. Sci., 50, I6r-r 7o.

Skorik I. T., Bekeney V. A., PAtjukova A. E., r97o. Energy metabolism in fattening pigs. Svinovodstvo, 12, 23-24.

Smith C., I962. Estimation of genetic change in farm livestock using field records. Anim. Prod., 4, $239-25 z$.

SmiтH C., 1967. Improvement of metric traits through specific genetic loci. Anim. Prod., 9, 349-358.

Smith C., KING J. W. B., GIrBERT N., I962. Genetic parameters of British Large White bacon pigs. Anim. Prod., 4, I $28-143$.

Smith C., Ross G. J. S., r965. Genetic parameters of British Landrace bacon pigs. Anim. Prod., 7, 29 I-3OI.

SUTHERLAND T. M., I965. The correlation between feed efficiency and rate of gain, a ratio and its denominator. Biometrics, 21, 739-749.

ThORBEK G., 1975. Studies on energy metabolism in growing pigs. 424. Beret. Statens Husdyrbrugs forsøg, I59 p., Kobenhavn. 
vaN Es A. J. H., I970. Stimulation of the growth of veal calves fed liquid milk replacers. In A. Schurch et C. Wenk, Energy Metabolism of Farm animals, EAAP Publ. no 13, 97-100, J. Druck éd., Zurich.

VANGEN O., 1974. Growth rate and feed conversion in lines of pigs selected for rate of gain and thickness of backfat. Acta Agric. Scand., 24, 309-318.

VERSTEgen M. W. A., Brascamp E. W., VAN dek Hel W., DE Groot P. N., Eikelenboom G., 1976. Effect of susceptibility to the malignant hyperthermia syndrome (MHS) as detected by halothane on some production and energy balance characteristics in Dutch Landrace pigs. In Proc. 3rd intern. Conf. on Prod. Disease in Farm Animals, 188-192, Pudoc, Wageningen.

Warson J. H., I97o. Les interactions de la génétique et de la nutrition dans les productions animales. Les Industries de l'alimentation animale, 220, 17-29.

WEBB A. J., KING J. W. B., 1976. Development of a synthetic pig sire line by selection with immigration. I. Results of selection and heritability estimates. Anim. Prod., 22, 23 I-244.

WEBB A. J., SмITH C., I976. Some preliminary observations on the inheritance and application of halothane-induced MHS in pigs. In Proc. 3 rd intern. Cont. on Prod. Disease in Farm Animals, 2II-2I3, Pudoc, Wageningen.

Webster A. J. F., SMith J. S., MOLlison G., 1976. On the prediction of heat production in growing cattle. In M. VERMOREL, Energy metabolism of Farm animals, EAAP Publ. no $\mathbf{n}^{\circ}$, $22 \mathrm{I}-224$, G. de Bussac éd., Clermont-Ferrand.

WENK C., VAN ES A. J. H., 1976. Energy metabolism of growing chickens as related to their physical activity. In M. VERMOREL, Energy metabolism of Farm animals, EAAP Publ. $\mathrm{n}^{\circ}$ I9, I89-I9z, G. de Bussac éd., Clermont-Ferrand.

Widar J., ANSay M., Hansér R., I975. Allozymic variation as an estimate of heterozygosity in Belgian pig breeds. Anim. Blood Grps biochem. Genet., 6, 22 I-234.

WIESEMÜLLER W., I976a. Theoretische Ableitung eines Leistungsabhängigen Lysinbedarfes fur Mastchweine. Wissenschaftliche Zeischrift derWilhem-Pieck Universität Rostock, 25, 147-149.

WIESEMïLLER W., I976b. Aminosäurenbedarf und-bedarfsdeckung bei Schweinen. Wissenschaftliche Zeitschrift der Wilhem-Pieck Universitäl Rostock, 25, I 5 I-163.

WILLEKE H., RICHTER L., I976. Effizienz eines privaten Schweinezuchtprogrammes im Vergleich zur regionalen Herdbuchzucht. $27^{\mathrm{e}}$ Réunion annuelle de la Féd. europ. Zootech., Zurich, 23-26 août.

Young L. D., Johnson R. K., OMTvedT I. T., WALTERS L. E., I976. Postweaning performance and carcass nierit of purebreds and two-breed cross pigs. J. Anim. Sci., 42, I Iz4-II3z. 